\title{
Sensitivity analysis of transient heat and moisture transfer in a bio-based date palm concrete wall
}

\author{
Tarek Alioua ${ }^{1,2}$, Boudjemaa Agoudjil $^{2}$, Abderrahim Boudenne $^{1^{*}}$, Karim $^{2}$ \\ Benzarti $^{3}$ \\ ${ }^{1}$ Univ Paris Est Creteil, CERTES, F-94010 Creteil, France \\ ${ }^{2}$ Université Batna -1, LPEA, Les Allées 19 Mai Route de Biskra Batna, Algeria \\ ${ }^{3}$ Lab Navier, Univ Gustave Eiffel, ENPC, CNRS, F77447 Marne la Vallée, France
}

\section{Abstract}

Hygrothermal mathematical models are commonly used to describe heat and moisture transfer in porous and bio-based building construction materials. This allows to evaluate their thermal insulation capacity, as well as their ability to regulate external climatic conditions and ensure indoor comfort for inhabitants. In this paper, a sensitivity analysis is performed on Kunzel's model, while it is applied to simulate the hygrothermal behavior of a wall structure made of a new bio-based building material (cement composite including date palm fibers). In a first part, the effects of finite variations of material properties/boundary conditions on the model's outcome are investigated. In a second step, specific transfer modes are neglected in the model, in order to study their influence on the numerical predictions. The results of this parametric study show that special attention should be paid to few parameters (heat capacity and density for heat transfer, sorption isotherm and water vapor resistance factors for moisture transfer) at the expense of others. Uncertainties on these influent parameters may result in large error accumulation, especially when modeling the moisture transfer process. Furthermore, initial boundary conditions and sensors position appear to be possible sources of discrepancies in the calculated RH profiles. Finally, the pure conduction model is found to provide good estimation of the temperature profiles compared to the full model, whereas liquid transfer must always be taken into account in the model to ensure accurate $\mathrm{RH}$ predictions through a bio-based date palm concrete wall.

Key words: heat and moisture transfer, sensitivity analysis, uncertainties, bio-based building materials, date palm concrete. 
$1 \quad *$ Corresponding authors:

2 *Pr. Abderrahim Boudenne, email: boudenne@u-pec.fr

3 Université Paris-Est Créteil Val de Marne, (UPEC)/CERTES, 61 Av. du Général de Gaulle 494010 Créteil cedex, France.

5

$6 \quad *$ Pr. Boudjemaa Agoudjil, email: boudjemaa.agoudjil@univ-batna.dz

7 Université Batna 1, 1rue chahid Boukhlouf Mohamed El-hadi 05000 Batna, Algeria.

8

9 


\section{Nomenclature}

$2 A_{c}$

$3 b$

$4 C_{p}$

$5 D_{l}$

$6 D_{l, w s}$

$7 D_{l, \varphi}$

$8 G_{\Omega}$

$9 h$

$10 l_{v}$

$11 p_{\text {sat }}$

$12 p_{v}$

$13 Q_{\Omega}$

$14 S$

$15 t$

$16 T$

$17 w$

$18 W$

$19 W_{f}$

$20 x$

$21 \quad Y$

$22 \beta$

$23 \delta$

$24 \quad \delta_{a}$

$25 \xi_{\varphi}$

$26 \lambda$

$27 \mu$

$28 \mu^{*}$

$29 \rho$

$30 \varphi$

31 Scripts: water absorption coefficient $\left(\mathrm{kg} \mathrm{m}^{-2} \mathrm{~s}^{-1 / 2}\right)$

moisture supplement of thermal conductivity (-)

material's heat capacity $\left(\mathrm{J} \mathrm{kg}^{-1} \mathrm{~K}^{-1}\right)$

liquid conduction coefficient under relative humidity gradient $\left(\mathrm{kg} \mathrm{m}^{-1} \mathrm{~s}^{-1}\right)$

capillary transport coefficient for suction process $\left(\mathrm{kg} \mathrm{m}^{-1} \mathrm{~s}^{-1}\right)$

liquid conduction coefficient in hygroscopic region $\left(\mathrm{kg} \mathrm{m}^{-1} \mathrm{~s}^{-1}\right)$

vapor flux at the boundary surface $\left(\mathrm{kg} \mathrm{m}^{-2} \mathrm{~s}^{-1}\right)$

exterior heat transfer coefficient $\left(\mathrm{W} \mathrm{m}^{-2} \mathrm{~K}^{-1}\right)$

latent heat of vaporization $\left(\mathrm{J} \mathrm{kg}^{-1}\right)$

vapor saturation pressure $(\mathrm{Pa})$

vapor pressure $(\mathrm{Pa})$

heat flux at the boundary surface $\left(\mathrm{W} \mathrm{m}^{-2}\right)$

relative sensitivity $(\%)$

time (s)

temperature $(\mathrm{K})$

water content $\left(\mathrm{kg} \mathrm{m}^{-3}\right)$

water content given by sorption isotherm $\left(\mathrm{kg} \mathrm{m}^{-3}\right)$

water content at free saturation $\left(\mathrm{kg} \mathrm{m}^{-3}\right)$

model's parameter

model's solution ( $T$ or $\varphi$ )

water vapor transfer coefficient at boundaries $\left(\mathrm{kg} \mathrm{m}^{-2} \mathrm{~s}^{-1} \mathrm{~Pa}^{-1}\right)$

water vapor permeability of the material $\left(\mathrm{kg} \mathrm{m}^{-1} \mathrm{~s}^{-1} \mathrm{~Pa}^{-1}\right)$

water vapor permeability of air $\left(\mathrm{kg} \mathrm{m}^{-1} \mathrm{~s}^{-1} \mathrm{~Pa}^{-1}\right)$

sorption capacity $\left(\mathrm{kg} \mathrm{m}^{-3}\right)$

thermal conductivity $\left(\mathrm{W} \mathrm{m}^{-1} \mathrm{~K}^{-1}\right)$

vapor diffusion resistance factor in dry conditions (-)

vapor diffusion resistance factor at higher humidity (-)

density $\left(\mathrm{kg} \mathrm{m}^{-3}\right)$

relative humidity (-) 


$\begin{array}{lll}1 & 0 & \text { at dry state or reference value } \\ 2 & a m b & \text { ambient } \\ 3 & c & \text { convection } \\ 4 & l & \text { liquid } \\ 5 & r & \text { radiation } \\ 6 & v & \text { vapor } \\ 7 & \Omega & \text { at boundaries } \\ 8 & & \end{array}$

9 


\section{$1 \quad 1 \quad$ Introduction}

2 Bio-composites based on vegetal fibers are still an extensive field of research in the construction sector, as they can contribute to reduce energy consumption in buildings thanks to their low thermal conductivity and high thermal inertia [1]. Besides, these materials have the capacity to regulate both temperature and relative humidity $(\mathrm{RH})$ of the indoor environment, offering in most cases an improved hygrothermal comfort for inhabitants [2].

So far, most studies dedicated to bio-based building materials were conducted at the sample scale and focused on the determination of various material characteristics, such as mechanical strength or heat/moisture storage and transmissibility properties (i.e. thermal conductivity, water vapor permeability, sorption isotherm, etc.). These works considered natural wastes of about 25 different kinds of plants, which were introduced/mixed in conventional construction materials [3]. Examples of well-known fibrous wastes from the biomass and used in this field are hemp [4], straw [5], date palm [6], wood [7] and flax [8]. These studies highlighted the good insulating properties of bio-based materials, as well as their ability to mitigate temperature and RH variations.

Since they obtained interesting results at the material level, researchers started to investigate the performance of these bio-based building materials under more realistic conditions at larger scales. Nevertheless, as experimental studies at the wall and building scales require huge equipment and can be very expensive, many researchers focused on the development of theoretical approaches. Since classical heat transfer models have shown limits when applied to bio-based materials [9], this work is focused on models considering coupled heat and mass transfer processes, which were proven effective in the case of building materials, even for those including natural fibers. Mathematical modeling of heat and mass transfer in porous materials was first carried out by by Phillip and De Vries in the case of soil structures [10], and their work served as a solid basis for the development of subsequent models. In 1995, Kunzel [11] developed his own model based on a thorough investigation of heat and mass transport mechanisms in porous building materials. Since then, Kunzel's model has been widely used by researchers in the field of bio-based building materials, and has also been validated by comparison with experimental evidences in several works $[12,13]$.

Hygrothermal models are commonly used to describe heat and mass transfer in building envelopes (walls, roofs, floors ...etc.). At the building scale, these models are usually combined 
1 least of two equations that describe heat and moisture transfer processes, and involve two 2 unknowns (i.e., temperature for heat transfer and $\mathrm{RH}$ or moisture content for moisture transfer).

3 In specific cases, air transfer is also considered in the problem, and a third equation is thus added to the previous system. The coefficients of these equations are generally defined in relation to actual experimental parameters. Some of these parameters are represented by single constant values, while others may depend on other material properties or on the system's unknowns themselves. The experimental determination of these parameters represents a source of errors, which may strongly influence or introduce bias in the final solution of the system [14, 15]. This issue has prompted some researchers to study the sensitivity of the hygrothermal models to variations of the different parameters, in order to improve as much as possible, the numerical estimations of both temperature and $\mathrm{RH}$.

Sensitivity analyses are very often adopted in almost all fields of research. The Global Sensitivity Analysis (GSA) is used to determine the sensitivity of model outputs to different inputs variations, and sensitivity indices are generally determined with the Monte Carlo method [16]. Differently, the Local Sensitivity Analysis (LSA) is used to assess the sensitivity of a model with respect to a given parameter [17]. In the field of hygroscopic building materials, the simulations are simply rerun for different parameter values/conditions, and the resulting new profiles are compared with the reference case. At the wall scale, Mendes et al. [18] carried out a sensitivity analysis on their model which is based on Phillip and De Vries theory. They defined different simplified sub-models in which they neglected or set constant specific transport coefficients, in order to evaluate their influence on the numerical results. The authors highlighted that neglecting moisture transfer in the model may lead to an underestimation of up to $59 \%$ of the yearly integrated heat flux, hence resulting in an underestimation of the overall energy consumption. Another work conducted by Bart et al. [14] studied the sensitivity of Kunzel's model to variations of the material density, thermal conductivity, heat capacity, vapor diffusion resistance factor, sorption curve and sensors position for the case of a hemp concrete wall. Results showed that theoretical RH profiles are mostly influenced by two parameters, i.e., the sorption isotherm and the vapor resistance factor. Kunzel's model was also studied by Oumeziane et al. [19], who investigated the effects of the material density and the initial conditions on the numerical results of a hemp concrete wall. It was concluded from this work,

31 that these parameters influence both the theoretical temperature and RH profiles, which was 32 explained by the coupling effects of heat and moisture transfer processes. Othmen et al. [15] carried out a sensitivity analysis on Kunzel's model at the wall scale as well using the LSA 
1 method. These authors studied the effect of several material properties, as well as the influence 2 of boundary and initial conditions in the case of two walls made of tuffeau and hemp concrete. 3 It was concluded from this analysis, that convective heat transfer coefficients influence both temperature and water content profiles, in addition to the adsorption isotherm that affects directly the water content distribution in the wall. At the building scale, Le et al. [2] performed another sensitivity analysis on Mendes model. They studied the impact of changes in the transport coefficients, sorption isotherm, ventilation rate and habitant's existence, on both indoor conditions and energy consumption. Once again, considering moisture transfer in the calculations had a significant effect on energy consumption, and this latter was also highly influenced by the ventilation rate.

Each of these works studied the sensitivity of hygrothermal models to various parameters or conditions, by considering a certain percentage of variation of these parameters/conditions with respect to their reference values. Moreover, some properties were considered constant, such as the thermal conductivity and sorption capacity. On the other hand, it was noticed that the results of the sensitivity analyses were sometimes different or contradictory if the models were applied to different materials under some specific experimental conditions [15]. This could be explained by the changes in material properties and conditions which may affect the kinetics of heat/moisture transfer. As a consequence, conclusions drawn from a sensitivity analysis should be restricted to the material under study.

In the present work, a comprehensive sensitivity analysis is carried out on Kunzel's hygrothermal model, while this latter is applied to Date Palm Concrete (DPC). To our very best knowledge, it is the first time this analysis is performed for this peculiar building material at the wall scale. The study is based on previous results obtained from an experimental campaign on a DPC at material and wall scales. DPC properties measured at material scale are used as reference input parameters in the model, while temperature and RH profiles collected from the DPC wall were used to validate the model's outcome that will be used in the sensitivity analysis as the reference solution. In this approach, the influence of a wide range of parameters (heat capacity $C_{p}$, exterior heat transfer coefficient $h$, thermal conductivity $\lambda$, vapor diffusion resistance factors $\mu$, density $\rho$ and sorption isotherm $W$ ), conditions and variation percentages are explored. A local sensitivity analysis (LSA) method

31 is used to capture separately the influence of each parameter on the model outcome, and the global influence of the whole set of parameters is then evaluated as well. The effects of initial/ boundary conditions and sensors 
1 positions on the values of temperature/RH calculated at different depths of the DPC wall are

2 also investigated. Finally, some terms of the hygrothermal model related to specific 3 heat/moisture transfer modes were neglected in order to investigate the possibility of

4 simplifying the model without affecting its accuracy.

$6 \quad 2 \quad$ Materials and methods

\section{$2.1 \quad$ DPC properties}

8 The material considered in this study is a new bio-based composite incorporating $15 \mathrm{wt}$. \% date 9 palm fibers in a classical mortar (cement + sand + water), and commonly referred to as Date Palm Concrete (DPC). This composite formulation was designed in previous studies [20-22], and was found to provide a good compromise between mechanical, thermo-physical and hygric properties. This DPC material offers both good thermal insulation/moisture buffering capacity, and also meets RILEM requirements for structural and insulating autoclaved aerated concretes $\left(\mathrm{Rc}>2.5 \mathrm{MPa}, \lambda<0.75 \mathrm{~W} \mathrm{~m}^{-1} \mathrm{~K}^{-1}\right)$ [21]. The main hygrothermal properties of this new DPC bio-composite were experimentally measured in our previous works and are reported in Table 1; these data will serve as reference inputs of the mathematical Kunzel's model in the framework of the sensitivity analysis.

The following sub-sections provide a brief description of the experimental methods used to determine these hygrothermal properties at the material scale.

\subsubsection{Vapor resistance factors}

21 Water vapor diffusion resistance factors $\mu$ and $\mu^{*}$ characterize the ability of the material to 22 oppose vapor transfer at different ranges of relative humidity. In the case of DPC, typical values were obtained using the dry and wet cup test method (EN ISO 12572 [23]).

\subsubsection{Capillary suction and free saturation}

Capillary suction is a liquid transfer mode which occurs mainly in the capillary region $(95 \%>$ $\mathrm{RH}>100 \%$ ). This process can be taken into account in the Kunzel's model through a water absorption coefficient $\left(A_{c}\right)$, whose value can be determined experimentally by suction process (EN ISO 15148 [24]). Free saturation defines the maximum liquid water storage capacity of a material after a total immersion, and is noted $W_{f}$. 


\subsubsection{Thermal conductivity, heat capacity and dry density}

Thermal conductivity $(\lambda)$ is an important property with regard to the insulation capacity of building materials, as it defines the ability of the medium to transmit a heat flux by conduction.

In this work, it is taken dependent on the moisture content $(w)$ according to [11]:

$$
\lambda(w)=\lambda_{0}\left(1+b \cdot \frac{w}{\rho_{0}}\right)
$$

Were $\lambda_{0}$ is the thermal conductivity at dry state and $b$ is the moisture supplement of thermal conductivity. In the case of DPC, values of these coefficients were calculated from thermal conductivity measurements. DPC density at dry state $\left(\rho_{0}\right)$ was also determined.

Heat capacity $C_{p}$ defines the amount of heat needed to change a material's temperature. It was determined experimentally for DPC.

Values collected for all these coefficients/properties in the case of DPC material are reported in Table 1, along with the references from which they are taken. They will be considered as reference values in the sensitivity analysis.

\subsubsection{Sorption isotherm}

Sorption isotherm represents the water retention evolution inside a material, during adsorption or desorption processes, as a function of relative humidity at a known temperature. For DPC, adsorption isotherm $W$ was obtained experimentally (EN ISO 12571 [24]) by Chennouf et al.

$8[22]$ at $23{ }^{\circ} \mathrm{C}$ and fitted with the GAB model (Guggenheim-Anderson-de Boer [26]).

9 Table 1: Reference values of the DPC properties

\begin{tabular}{|c|c|c|c|c|c|}
\hline Property & Value & Reference & Property & Value & Reference \\
\hline $\begin{array}{l}\text { Dry density }\left(\rho_{0}\right) \\
{\left[\mathrm{kg} \cdot \mathrm{m}^{-3}\right]}\end{array}$ & 954 & [20] & $\begin{array}{l}\text { Dry specific heat }\left(C_{p_{0}}\right) \\
{\left[\mathrm{J} \mathrm{kg}^{-1} \mathrm{~K}^{-1}\right]}\end{array}$ & 1500 & [21] \\
\hline $\begin{array}{l}\text { Dry thermal } \\
\text { conductivity }\left(\lambda_{0}\right) \\
{\left[\mathrm{W} \cdot \mathrm{m}^{-1} \mathrm{~K}^{-1}\right]}\end{array}$ & 0.185 & [20] & $\begin{array}{l}\text { Moisture supplement of } \\
\text { thermal conductivity }(b) \\
{[-]}\end{array}$ & 10.190 & [20] \\
\hline $\begin{array}{l}\text { Vapor resistance } \\
\text { factor (dry cup) }(\mu) \\
{[-]}\end{array}$ & 6.310 & [22] & $\begin{array}{l}\text { Vapor resistance factor } \\
\text { (wet cup) }\left(\mu^{*}\right) \\
{[-]}\end{array}$ & 5.570 & [22] \\
\hline
\end{tabular}




\begin{tabular}{lll|lll}
\hline $\begin{array}{l}\text { Water absorption } \\
\text { coefficient }\left(A_{c}\right)\end{array}$ & 0.165 & {$[20]$} & Water content at free & & \\
& & & \\
{$\left[\mathrm{kg} \cdot \mathrm{m}^{-2} \mathrm{~s}^{-0.5}\right]$} & & {$\left[\mathrm{kg} \cdot \mathrm{m}^{-3}\right]$} & 429 & {$[20]$} \\
\hline
\end{tabular}

\subsection{Experimental test at the wall scale}

3 For more realistic tests, boundary conditions to be used in the sensitivity analysis were imported

4 from an actual experimental campaign. A DPC wall of dimensions $50 \times 40 \times 15 \mathrm{~cm}^{3}$ (Fig. 1a) was

5 fabricated and then insulated from lateral surfaces using polystyrene panels and plastic film in

6 order prevent heat/moisture transfer through these surfaces and get a one-dimensional transfer across the thickness of the wall. Polystyrene panels were used to create a passive cell at the right side of the DPC wall, which represents the indoor environment (Fig. 1b). Three humidity/temperature sensors model DKRF400 from Driesen + Kern, Germany (measurement range of RH: $0-100 \%$ with an accuracy of $\pm 1.8 \%$, and measurement range of $\mathrm{T}:-40^{\circ} \mathrm{C}$ to $+45^{\circ} \mathrm{C}$ with an accuracy of $\pm 0.5^{\circ} \mathrm{C}$ ) were inserted at three different depths of the wall for data acquisition (at $3 \mathrm{~cm}, 7.5 \mathrm{~cm}$ and $12.5 \mathrm{~cm}$ from the outer surface). The reason behind choosing these specific depths was to enable measurements of temperature and $\mathrm{RH}$ close to the inner / outer environments and at the middle of the wall as well, in order to evaluate the response of the material at these locations. The overall setup was placed in a climatic chamber that represents the outdoor environment and enables to apply dynamic boundary conditions to the external side of the wall (Fig. 1.b). Two additional sensors were used to monitor both temperature and $\mathrm{RH}$ values in the indoor and outdoor environments.

Hygrothermal scenarios applied to the DPC wall using the regulation system of the climatic chamber are described as follows:

1) An initial step change of temperature from $23^{\circ} \mathrm{C}$ to $40^{\circ} \mathrm{C}$, followed by 4 repeated temperature cycles of 24 hours (hot/cold periods of 12 hours with step changes of temperature between $40^{\circ} \mathrm{C}$ and $18^{\circ} \mathrm{C}$ ) at constant humidity level of $50 \% \mathrm{RH}$. This scenario simulates the daily temperature variation during summertime,

2) An initial step change of $\mathrm{RH}$ from $23 \%$ to $75 \%$ followed by a prolonged exposure to $75 \%$ RH for 9 days at constant temperature $\left(23^{\circ} \mathrm{C}\right)$. Afterwards, another step RH change was applied from $75 \%$ to $33 \%$, and this latter level was maintained for another 9 days, still at constant temperature of $23^{\circ} \mathrm{C}$. The total duration of this scenario is 18 days. 
1 These scenarios were applied as outdoor conditions using the climatic chamber, while indoor

2 conditions were left uncontrolled. After every test, the wall was reconditioned at relative

3 humidity $\varphi=50 \%$ and $\mathrm{T}=23{ }^{\circ} \mathrm{C}$ which represent the initial conditions for the next test.

4 Details of the used scenarios are displayed in Table 2. Additional details regarding the

5 experimental setup and the protocols can be found in [27, 28].

7 Table 2: Outdoor conditions (values in brackets correspond to the initial conditions at the beginning

8 of the experiment, i.e. $23^{\circ} \mathrm{C}$ and $50 \% \mathrm{HR}$ )

\begin{tabular}{|c|c|c|c|}
\hline \multirow{2}{*}{ Scenarios } & \multicolumn{2}{|c|}{ Outdoor conditions } & \multirow{2}{*}{ Duration } \\
\hline & $\mathrm{T}\left[{ }^{\circ} \mathrm{C}\right]$ & $\varphi[\%]$ & \\
\hline Scenario 1 & $(23) \rightarrow 40 \rightarrow 18$ & 50 & $\begin{array}{l}4 \text { cycles of } 24 \text { hours }\left(12 \mathrm{~h} \text { at } 40^{\circ} \mathrm{C},\right. \\
\left.12 \mathrm{~h} \text { at } 18{ }^{\circ} \mathrm{C}\right)\end{array}$ \\
\hline Scenario 2 & 23 & $(50) \rightarrow 75 \rightarrow 33$ & $\begin{array}{l}18 \text { days (9 days at } 75 \% \mathrm{RH}, 9 \text { days at } \\
33 \% \mathrm{RH})\end{array}$ \\
\hline
\end{tabular}

9
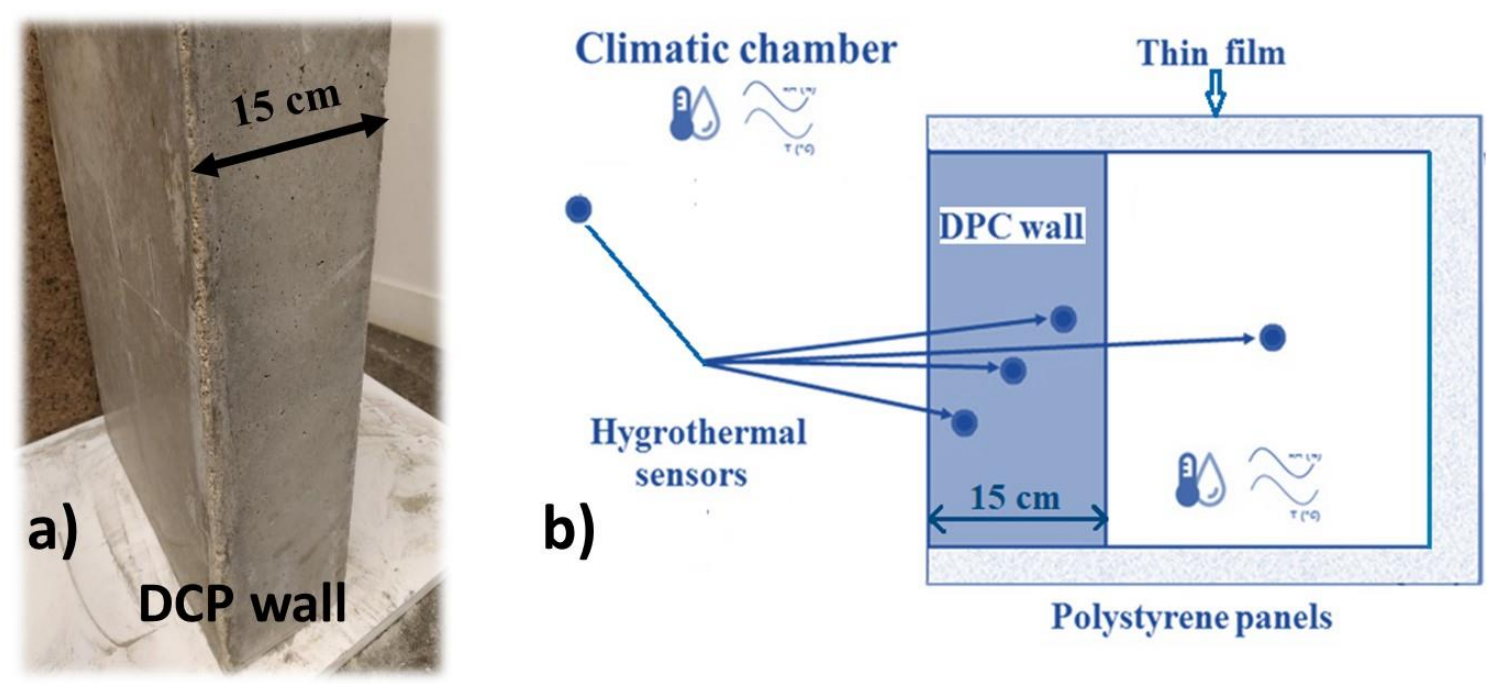

10

Fig. 1: The DPC wall (a) and schematic view of the experimental setup (b) 


\section{Mathematical formulation}

\section{$2 \quad 3.1 \quad$ Mathematical model}

3 All mathematical models describing heat and mass transfer in porous material are derived from

4 basic conservation equations. In porous media, some hypotheses are usually applied in order to 5 simplify the models [29], such as:

- The studied material is considered isotropic,

- The local thermodynamic equilibrium is reached between the different phases,

- Air and vapor are considered as ideal gases,

- Radiative heat transfer and chemical reactions are neglected inside the studied material, The mathematical model describing heat and moisture transfer in porous building materials and used in this study refers to Kunzel [11]. Based on the previous assumptions, the model is written as follows:

Moisture transfer

$$
\xi_{\varphi} \frac{d \varphi}{d t}=\frac{\partial}{\partial x}\left(\delta \frac{\partial\left(p_{s a t} \varphi\right)}{\partial x}+D_{l} \frac{\partial \varphi}{\partial x}\right)
$$

Heat transfer

$$
\left(\rho_{0} C_{p_{0}}+C_{p_{l}} w\right) \frac{d T}{d t}=\frac{\partial}{\partial x}\left(\lambda \frac{\partial T}{\partial x}\right)+l_{v} \frac{\partial}{\partial x}\left(\delta \frac{\partial p_{s a t} \varphi}{\partial x}\right)
$$

The transfer modes considered in this model are: diffusion of liquid water and vapor in the case of mass transfer, heat conduction and phase change heat for heat transfer. This model neglects air transfer because of the small variations of the total pressure in the case of building components [11].

The liquid water transport takes place according to several processes that are expressed in the model by the following coefficients [11]:

a) The liquid conduction coefficient (acts mainly in the hygroscopic region), defined as follows:

$$
D_{l, \varphi}=P_{s a t} \delta_{a}\left(\frac{1}{\mu^{*}(\varphi)}-\frac{1}{\mu}\right)
$$

Where $\mu$ and $\mu^{*}(\varphi)$ are vapor resistance factors obtained from dry and wet cup tests respectively. 
b) The capillary transport coefficient for suction process (acts mainly in capillary region):

$$
D_{l, w s}=\left(3.8\left(\frac{A_{c}}{W_{f}}\right)^{2} \cdot 1000 \frac{w}{w^{f}}-1\right) \xi_{\varphi}
$$

$3 \quad A_{c}$ and $W_{f}$ are measured experimentally (cf. section 2.1).

c) Liquid transport coefficient of redistribution; it is estimated as one decimal power bellow the capillary transport coefficient $D_{l, w s}$.

\subsubsection{Boundary conditions}

Experimental boundary conditions were defined and simulated according to Kunzel's work [11]. Heat and mass fluxes are equal to:

$$
\begin{aligned}
Q_{\Omega} & =h\left(T_{\Omega}-T_{a m b}\right) \\
G_{\Omega} & =\beta\left(P_{v, \Omega}-P_{v, a m b}\right)
\end{aligned}
$$

$h$ takes into account both convection and radiation through the following relation:

$$
\boldsymbol{h}=\boldsymbol{h}_{\boldsymbol{r}}+\boldsymbol{h}_{\boldsymbol{c}}
$$

And $\beta$ is the water vapor transfer coefficient at boundaries, defined as:

$$
\beta=7.10^{-9} \cdot h_{c}
$$

\subsection{Model validation}

Kunzel's model was widely used and compared with experimental data in previous studies from the literature. The Fraunhofer Institute for Building Physics has developed a software (Wufi) to describe the hygrothermal behavior of building envelops based on Kunzel's, which was validated by comparison with experimental evidences. A good agreement was reported between theoretical/experimental data for both temperature and RH profiles [13].
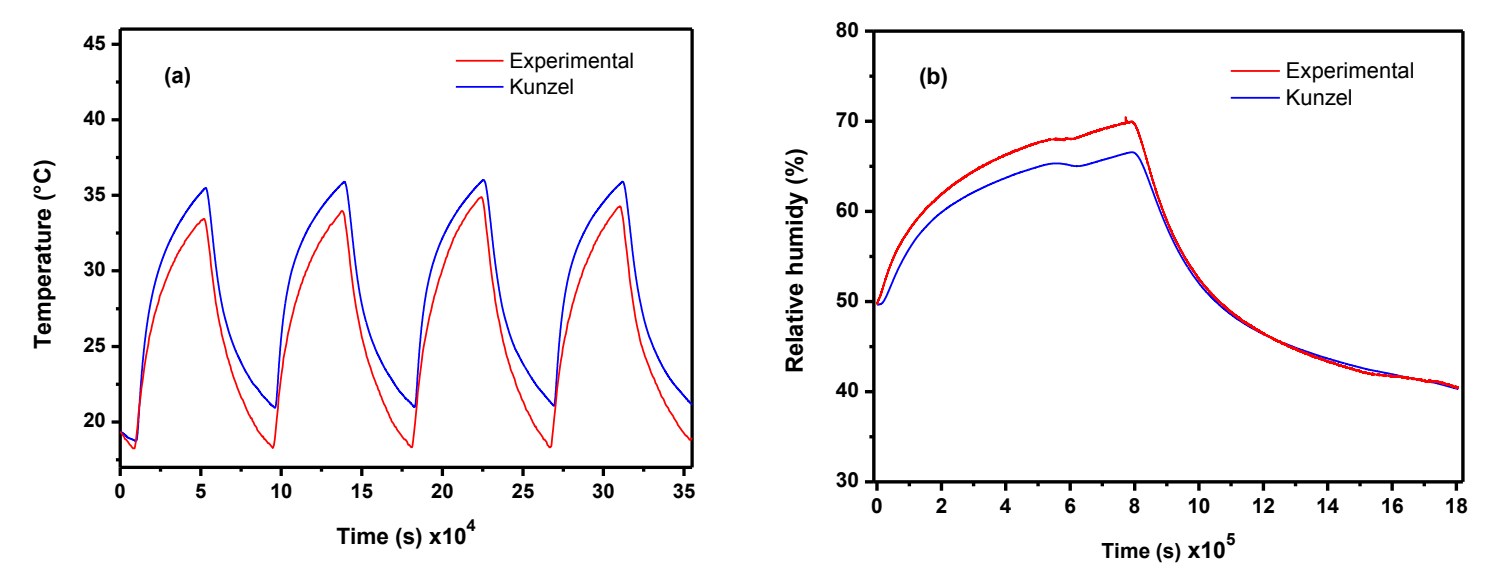
1 Fig. 2: Kunzel's model validation: comparison of experimental and numerical profiles at $3 \mathrm{~cm}$ depth inside the DPC wall, for temperature (a) and relative humidity (b)

Recently, we carried out a detailed validation of Kunzel's model using COMSOL Multiphysics software in the case of a DPC wall, using the same setup and scenarios described in section 2.2 [12]. As an illustration, theoretical and experimental profiles obtained at a depth of $3 \mathrm{~cm}$ in the DPC wall for temperature (scenario 1) and RH variations (scenario 2), are presented in Fig. 2.a and 2.b, respectively. A relatively good agreement was obtained between Kunzel's theory and experimental data in both cases. Nevertheless, slight differences were noticed between numerical/experimental curves, which could relate to various sources of errors: uncertainties on test conditions, accuracy/position of the sensors or values of input parameters that were injected into the model.

\section{$4 \quad$ Assumptions and sensitivity analysis}

The goal of this work is to assess the influence of a wide range parameters and conditions on the response of the hygrothermal Kunzel's model. In this line, the impact of finite variations of several material parameters on the numerical results was evaluated (considering different percentages of variations of these inputs with respect to their reference values), as well as the effects of time, depth location inside the wall, initial conditions, sensors position, liquid transfer, phase change heat, etc. This is done for the case of a date palm concrete wall.

\subsection{Uncertainties on the supposed known model parameters}

The first part of the study deals with the influence of input material parameters on the model's outcome. Significant errors are usually present on these parameters, due to measurement uncertainties at the material scale, or to the use of these parameters at higher scales as mentioned earlier (wall and building scales). This latter reason (transition from the material to the wall scale) may be responsible for much higher uncertainties on input values, because manufacturing several blocks or a sample of large dimensions can probably generate a wider range of uncertainties on the materials properties and on the homogeneity of the system [19]. As mentioned before, different sensitivity analysis methods are available depending on the number of variables set to change together, such as the Global Sensitivity Analysis (GSA) and the Local Sensitivity Analysis (LSA). The GSA consists in determining the sensitivity of output quantities to the variations of different input parameters, while the LSA evaluates the sensitivity of an 
1 output quantity to the variation of a given input. In the field of hygroscopic building materials, 2 we are mainly interested in local methods where the simulations are simply rerun for different parameters values and conditions, and the new profiles are compared with the reference case. In the present work, to evaluate the influence of a varying parameter on the resulting temperature and RH profiles, the relative sensitivity index is calculated as follows [30]:

$$
S(\%)=\frac{\left|Y_{x-\Delta x}-Y_{x+\Delta x}\right|}{2 Y_{0}} .100
$$

Where $\boldsymbol{Y}$ is the solution of the model ( $\boldsymbol{T}$ or $\boldsymbol{\varphi}), \boldsymbol{Y}_{\mathbf{0}}$ is the reference solution obtained when no parameter is changed (all parameters are set to their reference values), $\boldsymbol{x}$ indicates the variable parameter and $\Delta \boldsymbol{x}$ the variation range.

This relative sensitivity index is calculated considering different percentages of variation of input parameters with respect to their reference values, ranging from $5 \%$ to $25 \%[2,14,19]$. Low percentages represent errors that may occur at the material scale, while high percentages are related to errors at higher scales due to the accumulation of small errors. The evolution of the sensitivity index will be discussed as a function of: time, depth location and percentage of variation of the parameters compared to their reference values.

The sensitivity of Kunzel's model has been investigated with respect to the following parameters: heat capacity $C_{p}$, exterior heat transfer coefficient $h$, thermal conductivity $\lambda$, vapor diffusion resistance factors $\mu$, density $\rho$ and sorption isotherm $W$ that is used to define the water content $w$ in the hygrothermal model (Eq. 3) under the thermodynamic equilibrium hypothesis.

In a first step, each parameter was changed separately considering different percentages of variation ( $\Delta x:-5 \%,+5 \%,-15 \%,+15 \%,-25 \%$ and $+25 \%$ of the reference value), while the other parameters were kept constant at their initial values. In a second stage, all the parameters were changed simultaneously using the same percentages of variation, and the sensitivity index was calculated for the variation of all these parameters together in order to reveal possible interactions between parameters. For example, for this last case, all parameters were varied with $-5 \%$ relating to their initial value, to obtain $\boldsymbol{Y}_{\boldsymbol{x}-\Delta \boldsymbol{x}}$ that is defined in Eq. 10. Then, all parameters were also varied with $+5 \%$ to obtain $\boldsymbol{Y}_{\boldsymbol{x}+\Delta x}$, Finally, these two last results allow to obtain the corresponding sensitivity index $\boldsymbol{S}$. This procedure was performed as well for the rest of percentages variation $\pm 15 \%$ and $\pm 25 \%$. 
1 The different configurations of this sensitivity analysis are summarized in Table 3 (including

2 the reference case). Calculations were carried out for the two scenarios previously described in 3 section 2.2 (cycles of temperature and RH, respectively). 43 different simulations were run for

4 each scenario, representing a total of 86 simulations for the overall study.

5 Some of these parameters represent independent coefficients $\left(C_{p}, h, \mu\right.$ and $\left.\rho\right)$ while other 6 parameters are defined as functions ( $\lambda$ defined by Eq. 1 and $W$ defined by the GAB model) and depend on other parameters or/and on the system's unknowns (temperature and relative humidity RH). It is worth to mention that changing some parameters may imply the change of others, i.e. changing the adsorption isotherm $W$ implies a systematical recalculation of $\xi_{\varphi}$, the sorption capacity that represents the derivative of the sorption isotherm. Moreover, the vapor resistance factors obtained from wet and dry cup tests $\left(\mu^{*}\right.$ and $\left.\mu\right)$, are both changed simultaneously with the same percentages and are used to calculate liquid conduction coefficient $\left(D_{l}\right)$ according to Eq. (4). In the same way, varying the heat exchange coefficient $h$ with a certain percentage leads to a variation with the same percentage of the convective heat transfer coefficient $h_{c}$, which is used to calculate the water vapor transfer coefficient at boundaries $\beta$ (see Eq. 9).

Besides, real boundary conditions imported from the actual experiment will be introduced in the model (instead of creating uniform functions numerically), in order to perform the sensitivity analysis under more realistic conditions. This choice will also facilitate future comparisons between numerical simulations and experimental measurements.

21 Table 3: Study cases of the sensitivity analysis (for each case, 6 different percentages of 22 variations and two scenarios were considered)

\begin{tabular}{cccc}
\hline Case & $\begin{array}{c}\text { Varying } \\
\text { parameters }\end{array}$ & $\begin{array}{c}\text { Variation } \\
\text { percentage }\end{array}$ & $\begin{array}{c}\text { Unchanged parameters } \\
\text { (set to their reference } \\
\text { values indicated in Table 1) }\end{array}$ \\
\hline Reference case & -- & -- & $C_{p}, h, \lambda, \mu, \rho, W$ \\
\hline Case 1 & $C_{p}$ & $\pm 5 \%, \pm 15 \%, \pm 25 \%$ & $h, \lambda, \mu, \rho, W$ \\
\hline Case 2 & $h$ & $\pm 5 \%, \pm 15 \%, \pm 25 \%$ & $C_{p}, \lambda, \mu, \rho, W$ \\
\hline Case 3 & $\lambda$ & $\pm 5 \%, \pm 15 \%, \pm 25 \%$ & $C_{p}, h, \mu, \rho, W$ \\
\hline Case 4 & $\mu$ & $\pm 5 \%, \pm 15 \%, \pm 25 \%$ & $C_{p}, h, \lambda, \rho, W$ \\
\hline Case 5 & $\rho$ & $\pm 5 \%, \pm 15 \%, \pm 25 \%$ & $C_{p}, h, \lambda, \mu, W$ \\
\hline
\end{tabular}




\begin{tabular}{cccc}
\hline Case 6 & $W$ & $\pm 5 \%, \pm 15 \%, \pm 25 \%$ & $C_{p}, h, \lambda, \mu, \rho$ \\
\hline $\begin{array}{c}\text { Case 7 } \\
\text { (simultaneous } \\
\text { variation) }\end{array}$ & $C_{p}, h, \lambda, \mu, \rho$, & $\pm 5 \%, \pm 15 \%, \pm 25 \%$ & -- \\
\hline
\end{tabular}

1

\subsection{Effect of initial conditions and sensors position}

Another common possible source of errors in numerical calculations is related to the initial conditions. In the present case, initial values of temperature and $\mathrm{RH}$ are imported from the experiment. Consequently, the sensors accuracy may be responsible for some uncertainties on the measured values. The hygrothermal sensors (model DKRF400 from Driesen + Kern, Germany) present an accuracy of $\pm 0.5^{\circ} \mathrm{C}$ on temperature and $\pm 1.8 \%$ on $\mathrm{RH}$. It should be noted that these sensors have a higher accuracy compared those usually used in other works.

Besides, insertion of the hygrothermal sensors into the DPC wall requires drillings holes in view of positioning the sensor's probe at a given depth. This is a rather tough operation, which may result in significant errors on the sensor position. In order to evaluate the bias caused on theoretical temperature and RH profiles, the effect of a deviation of the sensor location (up to $\pm 1 \mathrm{~cm}$ away from its reference position) on numerical results was investigated.

\subsection{Simplification of heat and moisture transfer models}

In the next part of the work, the possibility of simplifying the description of the transfer processes in the model was also investigated. In this line, some terms of the model related to specific transfer modes were neglected, and the effects of these modifications on the numerical outcomes were then evaluated by comparison with the reference case.

Such an investigation was already proposed in the literature [31]. Heat transfer was modeled by taking into account the conduction process only, and this simplified model proved to give good results in terms of temperature predictions.

In this part of the study, we explored the same hypothesis by neglecting the phase change term in the heat equation of the hygrothermal model (Eq. 3) and keeping only the heat conduction term. This leads to the following equation for heat transfer:

$$
\left(\rho_{0} C_{p_{0}}+C_{p_{l}} w\right) \frac{d T}{d t}=\frac{\partial}{\partial x}\left(\lambda \frac{\partial T}{\partial x}\right)
$$

This new model was solved for scenario 1, and the results obtained at different depth of the DPC wall were then compared to reference solutions provided by the complete model. 
1 Likewise, as far as porous building materials are concerned, huge importance is usually given

2 to vapor transfer at the expense of liquid water transfer while modelling transfer phenomena

3 and RH variations. In order to estimate the contribution of liquid water diffusion to the overall

4 moisture transfer process, this specific mode was neglected in the model by setting to zero the

5 liquid transfer coefficients (cf. section 3.1) of the mass transfer equation (Eq. 4), hence leading

6 to the following expression:

$$
\xi_{\varphi} \frac{d \varphi}{d t}=\frac{\partial}{\partial x}\left(\delta \frac{\partial\left(p_{s a t} \varphi\right)}{\partial x}\right)
$$

8 This simplified model, based on vapor diffusion only, was solved using conditions of scenario

92 , and numerical results obtained at various depth of the DPC wall were again compared to

10 those provided by the full model.

\subsection{Boundary conditions}

12 To resolve the problem, Kunzel's model was implemented in COMSOL Multiphysics, a 13 simulation software and partial differential equations solver based on the finite element (FE) 14 method [32]. The wall presented in section 2.2 was simulated and discretized following the 15 same procedure as in [12]. A schematic view of the simulated wall and boundary conditions is 16 presented in Fig. 3.

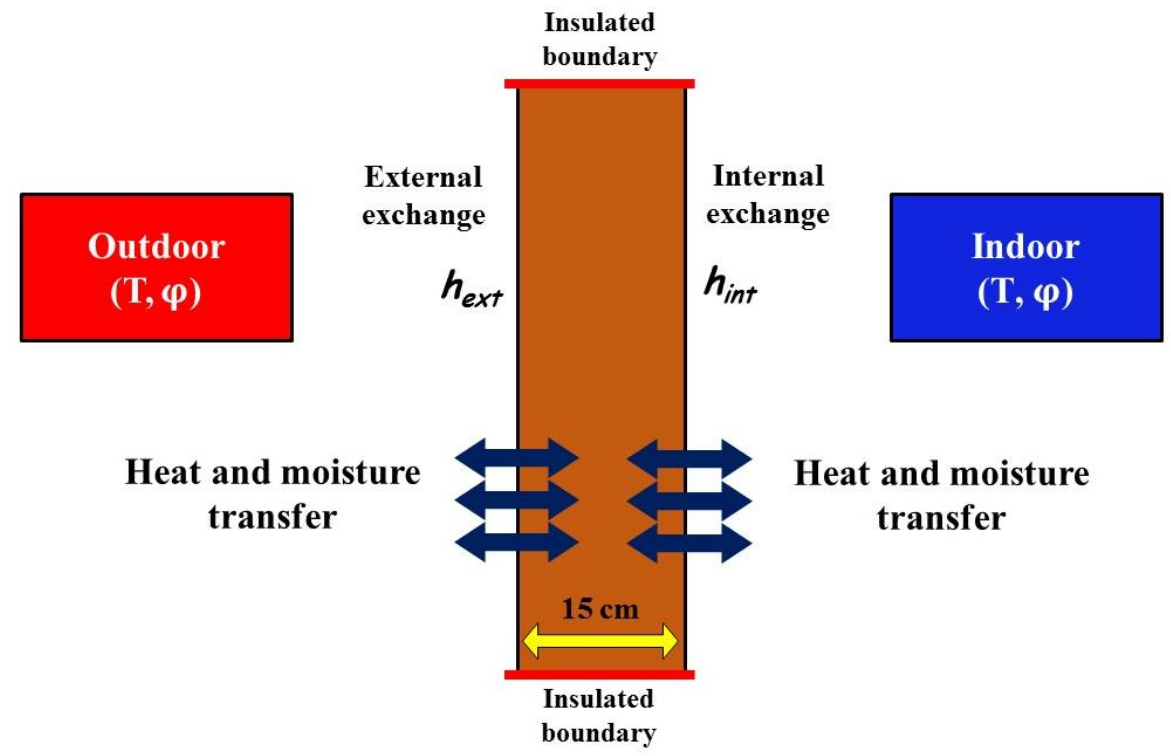

Fig. 3: Model of the simulated wall

The global heat transfer coefficients at boundaries were estimated as follows, according to

- $\quad 8 \mathrm{~W} \cdot \mathrm{m}^{-2} \cdot \mathrm{K}^{-1}$, with a convective contribution of $3.57 \mathrm{~W} \cdot \mathrm{m}^{-2} \cdot \mathrm{K}^{-1}$ for the interior surface, 
$1 \quad-17 \mathrm{~W} \cdot \mathrm{m}^{-2} \cdot \mathrm{K}^{-1}$, with a convective contribution of $10 \mathrm{~W} \cdot \mathrm{m}^{-2} \cdot \mathrm{K}^{-1}$ for the exterior surface.

\section{Results and discussion}

\section{$3 \quad 5.1 \quad$ Uncertainties on supposed known model parameters}

\section{$4 \quad$ 5.1.1 Reference solutions}

5 Reference solutions obtained at various depth of the DPC wall for scenarios 1 and 2 (heat and

6 moisture transfers) are respectively presented in Figs. 4 and 5. These results were obtained by

7 introducing into the model the reference values of input parameters (i.e., measured material

8 properties or estimated value in the case of the heat transfer coefficient $h$ ). These temperature

9 and RH profiles will be used as a reference curves for the sensitivity analysis.
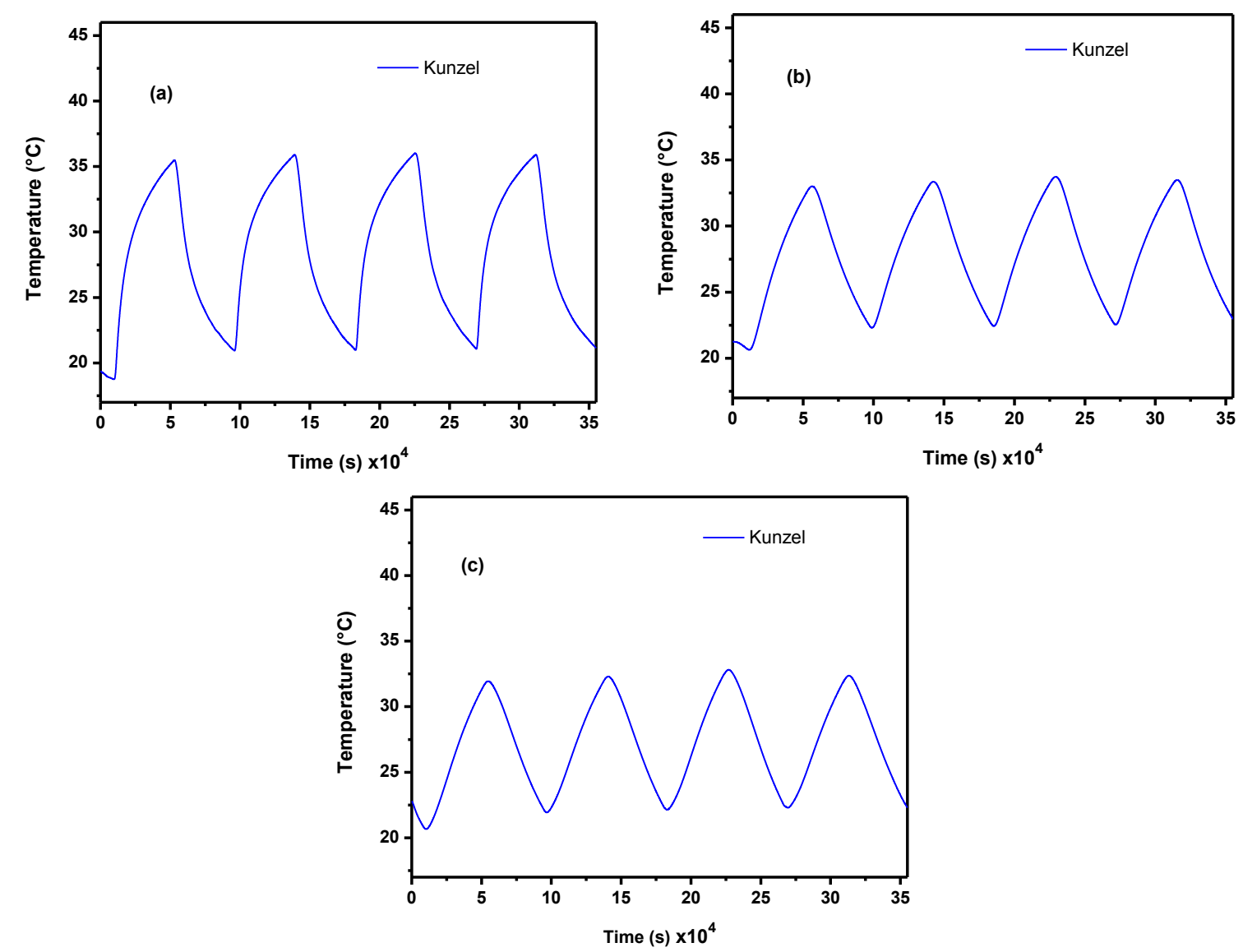

Fig. 4: Reference solutions of the temperature profiles at various depths of the DPC wall 24 subjected to scenario 1 (origin = outdoor side of the wall): $3 \mathrm{~cm}(\mathrm{a}), 7.5 \mathrm{~cm}(\mathrm{~b}), 12.5 \mathrm{~cm}(\mathrm{c})$. 

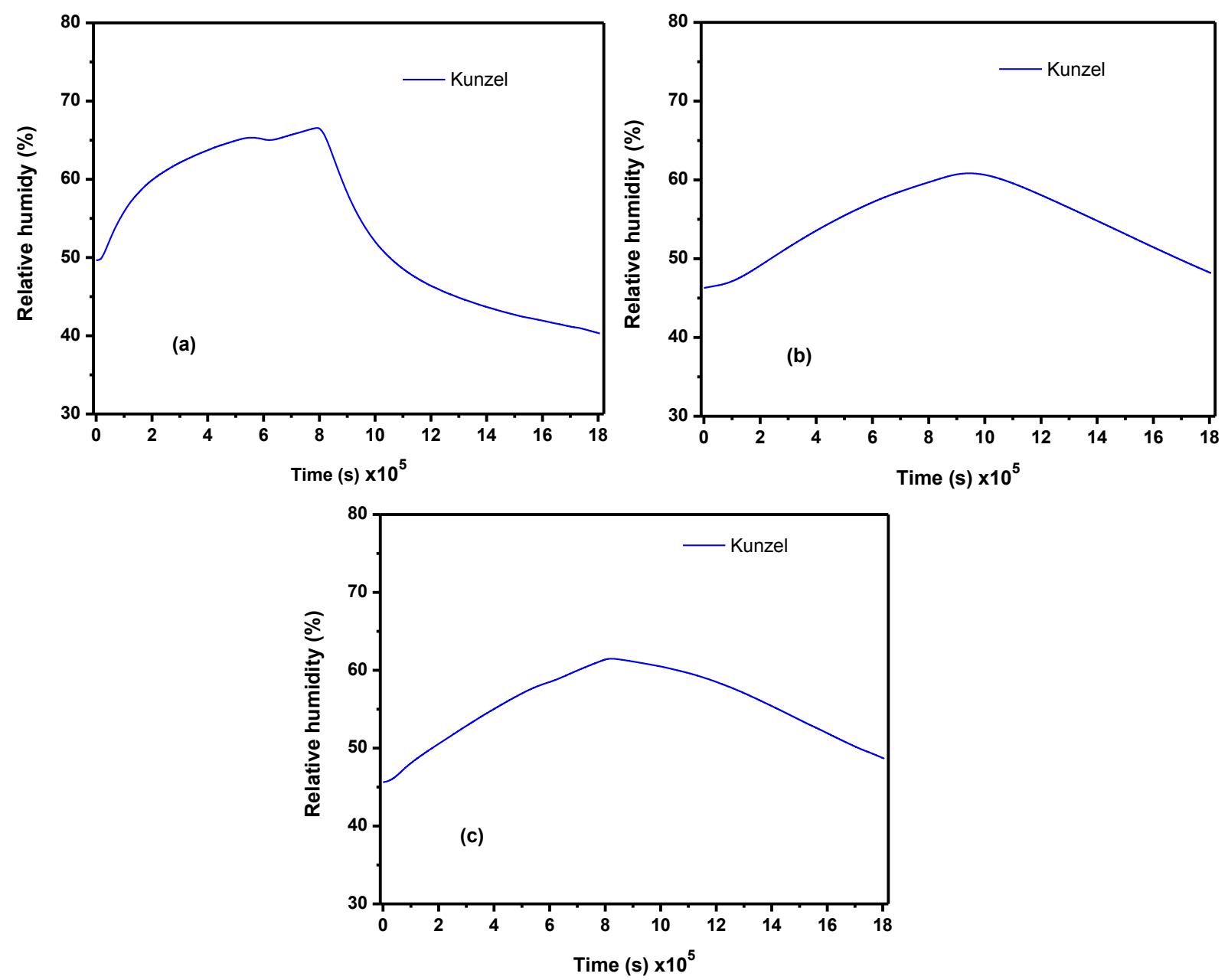

Fig. 5: Reference solutions of RH profiles at different depths of the DPC wall subjected to scenario 2 (origin at the outdoor side of the wall): $3 \mathrm{~cm}$ (a), $7.5 \mathrm{~cm}$ (b) and $12.5 \mathrm{~cm}$ (c).

\subsubsection{Sensitivity as a function of time}

5 In the current study, different factors may influence simultaneously the model's sensitivity for

6 the different input parameters: the percentage of variation of input parameters, time and depth

7 location. Therefore, we propose a methodology in which two of these factors are fixed, so that

8 the sensitivity evolution for the third factor can be assessed. In a first stage, the effect of time

9 evolution on the model's sensitivity to different input parameters is investigated for each

10 scenario. At first the effect of all parameters over time is displayed for a $25 \%$ variation

11 percentage at $3 \mathrm{~cm}$ depth (the effect at other depths is also presented below). This percentage

12 was chosen in order to show the extreme case of errors.

\section{$13 \quad$ Heat transfer (scenario 1)}


1 Fig. 6 shows the evolution over time of the relative sensitivity of the model to the various input 2 parameters, at a depth of $3 \mathrm{~cm}$ in the DPC wall and considering $25 \%$ variation on parameters 3 with respect to their reference values.

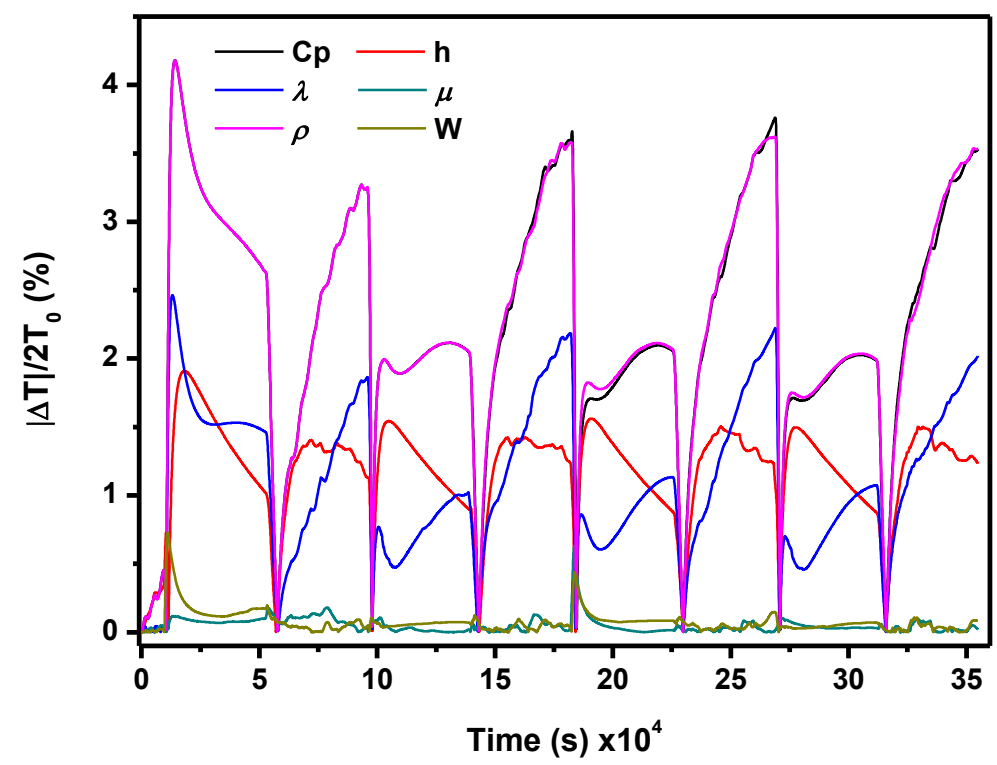

Fig. 6: Evolution over time of the relative sensitivity of the model to various input parameters, at $3 \mathrm{~cm}$ depth in the DPC wall and considering $25 \%$ of variation on parameters with respect to their reference values (case of scenario 1)

It can be observed that the various parameters do not have the same influence on the evolution curves of the temperature relative sensitivity. The most influencing parameters are respectively $C_{p}$ and $\rho$, followed by $h$ and $\lambda$, and finally $\mu$. Likewise, it seems obvious that the sorption isotherm $W$ and the water vapor resistance factor $\mu$ have a negligible impact in this case.

Besides, the curve obtained for the relative sensitivity to $h$ shows a very different trend (and even a reverse evolution) compared to the other curves: when the relative sensitivity to $h$ increases, the sensitivities to the other parameters are found to decrease, and vice versa. Moreover, sensitivities to $C_{p}$ and $\rho$ have almost the same evolutions. The same results were obtained by Le et al. [33] for a hemp concrete wall and the same variation percentage (25\%). These two parameters are usually linked together but we plotted each of them separately because their experimental values can be measured separately, and thus measurement errors can be made on both properties.

Fig. 7 displays the evolution versus time of the relative sensitivity to $C_{p}$ (this parameter has previously been identified as the most influencing parameter on heat transfer). Evolution curves 
1 are plotted for different depths of the DPC wall, at $3 \mathrm{~cm}, 7.5 \mathrm{~cm}$ and $12.5 \mathrm{~cm}$ away from the 2 outdoor side of the wall. It can be seen that the sensitivity index goes up and down 3 simultaneously at all depths.

4
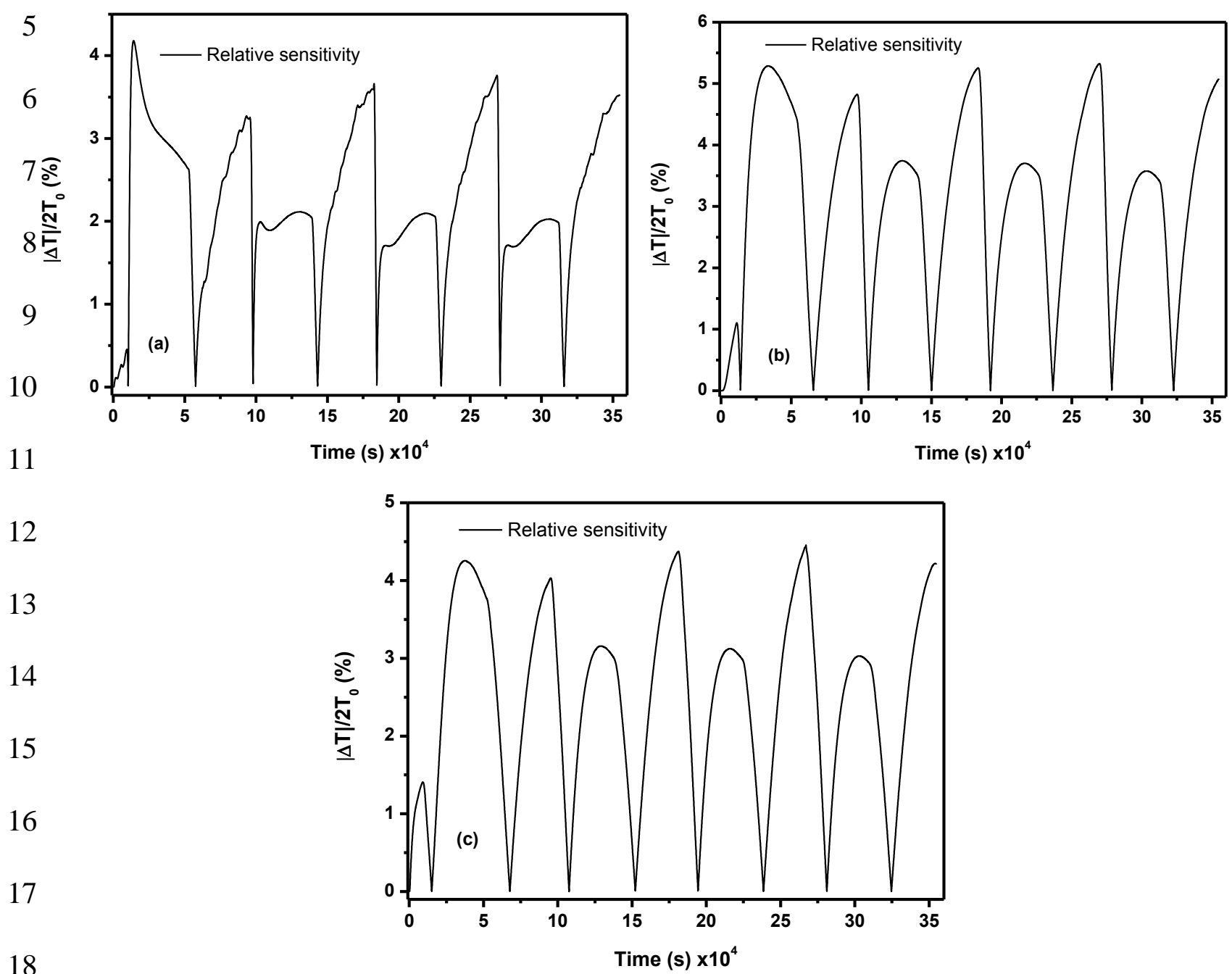

Fig. 7: Evolution versus time of the temperature relative sensitivity to a change of $25 \%$ in the heat capacity $\left(C_{p}\right)$ with respect to the reference value, and at different depths of the DPC wall: $3 \mathrm{~cm}(\mathrm{a}), 7.5 \mathrm{~cm}(\mathrm{~b})$ and $12.5 \mathrm{~cm}(\mathrm{c})$

23 Fig. 8 shows the evolutions of the new temperature profiles at different depths, which were calculated considering variations of $\pm 25 \%$ on $C_{p}$ with respect to the reference value

25 (reference curves are displayed on this graph as well). We can observe that the wall reacts in 26 the same way as external variations but with different amplitudes decreasing as a function of depth. This is 
1 due to the fact that we are moving away from the external surface where the outdoor 2 conditions (scenarios) are applied. By comparing Figs. 7 and 8, it is found that maximum 3 values of sensitivity are reached at the same time as the outdoor temperature reaches its 4 minimum during the imposed temperature cycle. Indeed, the quantity $\left|\boldsymbol{Y}_{\boldsymbol{x}-\Delta \boldsymbol{x}}-\boldsymbol{Y}_{\boldsymbol{x}+\Delta \boldsymbol{x}}\right|$ is 5 maximal at this point, and when divided by the minimum reference temperature, it gives 6 maximum values of the relative sensitivity (Eq. 9). This was the case for all depths.

7 We can also notice that the sensitivity curves (Fig. 7) are smoother at $7.5 \mathrm{~cm}$ and $12.5 \mathrm{~cm}$ depths, 8 compared to $3 \mathrm{~cm}$. This is due to temperature reference and new profiles which show also 9 smoother curves at $7.5 \mathrm{~cm}$ and $12.5 \mathrm{~cm}$ depths. Note that the first cycle was ignored in the result analysis to avoid any possible effect of initial conditions.
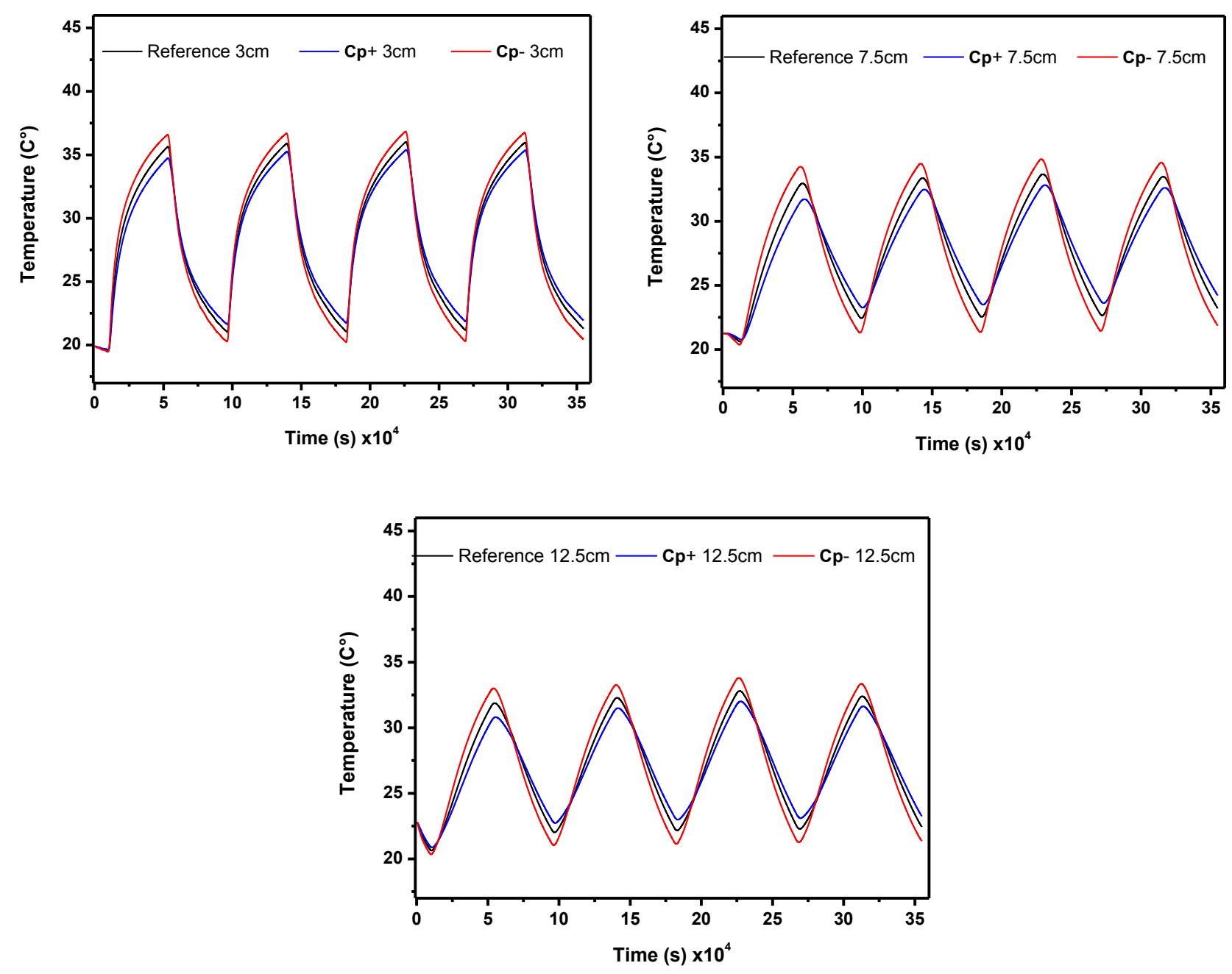

11 
Fig. 8: New temperature profiles simulated at different depths of the DPC wall, considering

2 variations of the heat capacity by $+25 \%\left(C_{p+}\right)$ or $-25 \%\left(C_{p_{-}}\right)$compared to the reference value

\section{$4 \quad$ Moisture transfer (scenario 2)}

5 Regarding moisture transfer (scenario 2), the most influencing parameters are the sorption 6 isotherm $W$ and vapor resistance factors $(\mu)$ whereas the other parameters have negligible 7 effects, as shown in Fig. 9.

8

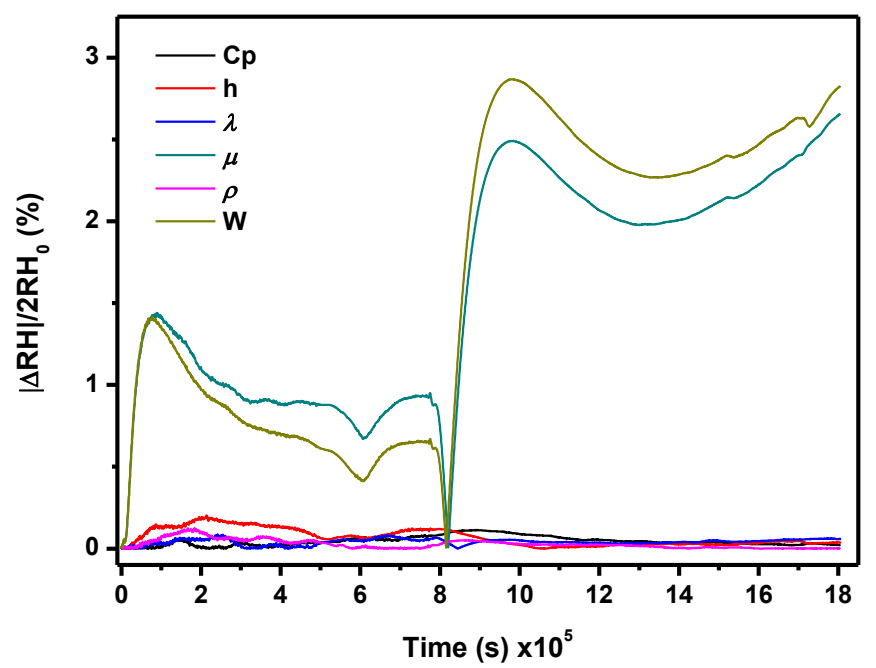

Fig. 9: Evolution over time of the relative sensitivity of the model to various input parameters, at $3 \mathrm{~cm}$ depth in the DPC wall and considering $25 \%$ of variation on parameters with respect to their reference values (for scenario 2).

Fig. 10 depicts the new RH profiles simulated considering variations of $+25 \%$ or $-25 \%$ on these two influent parameters, and at different depths of the wall. It was noted that lower values of $W$ and $\mu$ lead to higher $\mathrm{RH}$ curves during adsorption phase (i.e. max $\mathrm{RH}$ differences during adsorption phase for a $-25 \%$ sorption isotherm $W$ read: $0.63 \%, 1.29 \%$ and $0.85 \%$ at $3 \mathrm{~cm}, 7.5$ $\mathrm{cm}$ and $12.5 \mathrm{~cm}$ depth respectively) and lower curves during desorption phase (i.e. max RH differences during desorption phase for a $-25 \%$ sorption isotherm $W$ read: $1.28 \%, 2.31 \%$ and $1.39 \%$ at $3 \mathrm{~cm}, 7.5 \mathrm{~cm}$ and $12.5 \mathrm{~cm}$ depth respectively). A lower sorption isotherm corresponds to lower moisture storage in the material for the same RH value, this means that at a given water content, we get a higher RH with the new sorption isotherm. Thus, a decrease in water content 
1 resulted in slowing down the moisture transfer and storage in the material, as maximum and

2 minimum levels of $\mathrm{RH}$ were obtained with a time delay on the new profiles.

3 In the same way, a reduction of the vapor resistance factor $\mu$ implies more vapor diffusion in

4 the material, hence higher RH levels during adsorption phase and lower ones during desorption.

5 The same observations and conclusions were also reported by [14, 34].

6
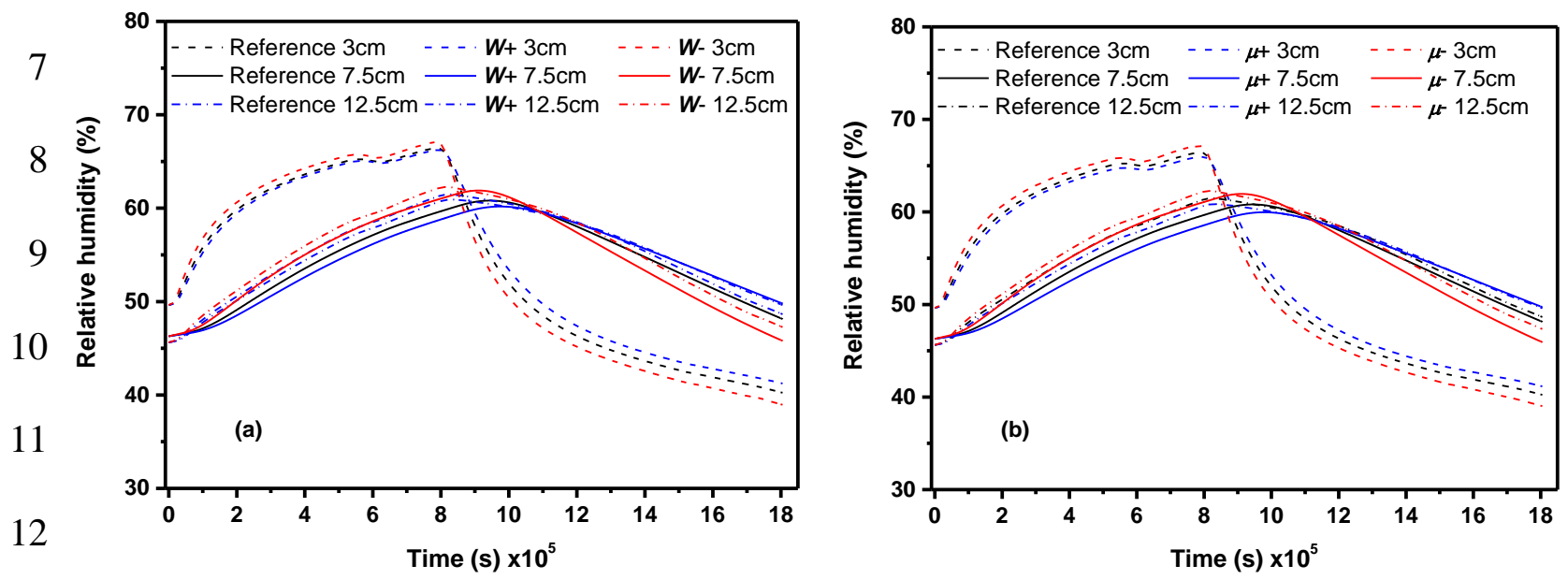

Fig. 10: New RH profiles simulated at different depths of the DPC wall, considering $\pm 25 \%$ variations on (a) the sorption isotherm $W$ and on (b) the vapor resistance factor $\mu$ compared to their reference values

Fig. 11 represents the evolution over time of the relative sensitivity of the model to a $25 \%$ variation on the sorption isotherm $W$, which was previously identified as the most influencing parameter on moisture transfer. Numerical curves obtained at different depths of the DPC wall are displayed. Larger variations can be observed at $3 \mathrm{~cm}$ depth compared to $7.5 \mathrm{~cm}$ and 12.5 $\mathrm{cm}$ depths (this is very similar to what was observed for the temperature relative sensitivity obtained in the case scenario 1). The relative sensitivity reaches minimum values (zero) at the points of the curves reversing shown on Fig. 10 (the points where the higher curve becomes lower and the lower one becomes higher). This is because the new curves intersect and $\mid \boldsymbol{Y}_{\boldsymbol{x}-\Delta \boldsymbol{x}}-$ $\boldsymbol{Y}_{\boldsymbol{x}+\Delta \boldsymbol{x}} \mid$ is equal to zero. Almost at all depths the highest relative sensitivity values were obtained at the end of the test. At these points, $\left|\boldsymbol{Y}_{\boldsymbol{x}-\Delta \boldsymbol{x}}-\boldsymbol{Y}_{\boldsymbol{x}+\Delta \boldsymbol{x}}\right|$ is maximum and $\boldsymbol{R} \boldsymbol{H}_{\mathbf{0}}$ is minimum. 

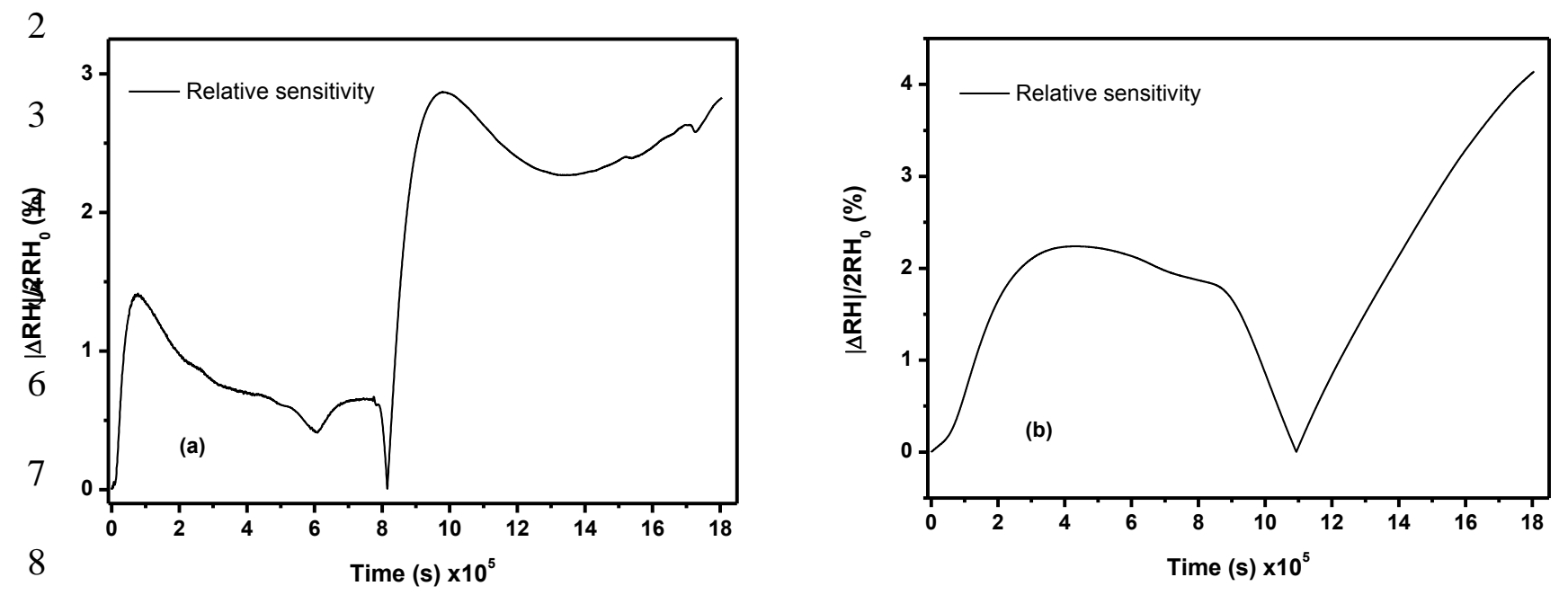

9

10

11

12

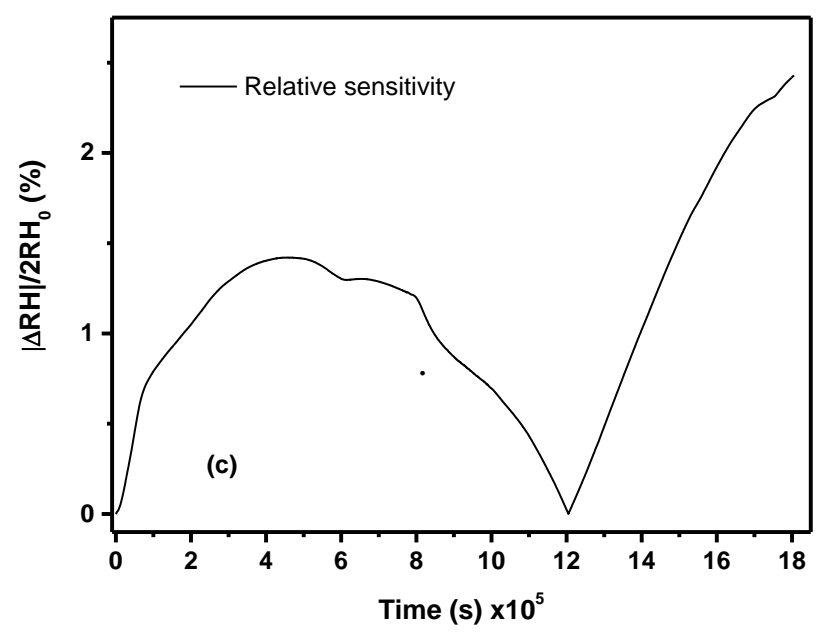

15

Fig. 11: Evolution over time of the RH relative sensitivity to a change of $25 \%$ in the sorption isotherm $(W)$ with respect to the reference value, and at different depths of the DPC wall: 3

$$
\mathrm{cm}(\mathrm{a}), 7.5 \mathrm{~cm}(\mathrm{~b}) \text { and } 12.5 \mathrm{~cm}(\mathrm{c}) \text {. }
$$

\subsubsection{Comparison of sensitivities to different parameters}

21 In a second stage, we compared the relative sensitivity of the model to each parameter at a fixed

22 time, and considering different variation percentages of the model inputs. Simulations were

23 carried out at different depths of the DPC wall. The time instants were chosen according to the

24 analysis reported in section 5.1.2. The principle was to choose instants where the relative sensitivity reaches maximum values, so that the maximal influences of the various parameters can be compared. Different time instants were selected, depending on the scenario and the depth position considered. 


\section{$1 \quad$ Heat transfer (scenario 1)}

2 As already mentioned, the first cycle was not considered in this analysis. The instants chosen

3 for the comparison are $t_{1}=268920 \mathrm{~s}, t_{2}=269760 \mathrm{~s}$ and $t_{3}=267120 \mathrm{~s}$ for $3 \mathrm{~cm}, 7.5 \mathrm{~cm}$ and 12.5

$4 \mathrm{~cm}$ depth respectively. They represent the instants where the sensitivity to $C_{p}$, the most

5 influencing parameter on heat transfer reach a maximum value. At these times and using the relative sensitivity expression (Eq. 9), the evolution of the sensitivity as a function of the variation percentage of each parameter was plotted in Fig.12. This figure displays the graphs determined at different depths of the DPC wall. In agreement with previous results of section 5.1.2, the most influencing parameters on the heat transfer were $C_{p}$ and $\rho$, then $h$ and $\lambda$, and finally $\mu$ and $W$. A similar ranking was observed at all depths. Similar results were obtained by Van Belleghem et al. [34], who studied the sensitivity of heat and mass transfer to moderate changes $(5 \%)$ in initial material properties, in the case of in gypsum boards. It can be noted that the sensitivity of the model to the external heat transfer coefficient $(h)$, decreases as a function of depth. This result was expected, due to the increasing distance from the outdoor surface of the wall.

Besides, the sensitivity of the model to a simultaneous change in the whole set of parameters (using the same variation percentage for all parameters) was found much lower compared to the sum of individual sensitivities. This result suggests that errors on input parameters don't accumulate and don't influence each other, or that they compensate each other in some way. In order to clear this up, the new temperature profiles simulated at $3 \mathrm{~cm}$ depth in the DPC wall considering a $25 \%$ variation on the most influencing parameters $\left(C_{p}, \rho, h\right.$ and $\lambda$, varied one by one while keeping the other parameters constant at their initial value) are represented in Fig. 13. One can notice that $C_{p}$ and $\rho$ influence the temperature profiles in an opposite way compared to $h$ and $\lambda$ : increasing the values of $C_{p}$ or $\rho$ in the model results in a larger amplitude of the simulated profiles, whereas higher values of $h$ and $\lambda$ tend to decrease this amplitude. This opposite trend confirms that, when parameters are changed simultaneously, compensation phenomena occurs and lower the resulting sensitivity of the model in comparison to the sum of individual sensitivities. However, since variations of $C_{p}$ and $\rho$ have similar effects, errors on these two parameters may accumulate and emphasize the difference of the model outcome compared to the reference response. The same comment can be made regarding accumulation of errors on $h$ and $\lambda$. 
1 It should be noticed that some of the cases considered in this sensitivity analysis may not be

2 representative of actual experimental configurations, because varying a specific parameter may

3 in reality imply changing one or several other parameters. For instance, Collet et al. [35]

4 reported that thermal conductivity of hemp concrete blocks is highly dependent on the material

5 density ( $\lambda$ increases as a function of $\rho$ ). Nevertheless, the present mathematical sensitivity

6 analysis remains relevant for parameters on which experimental errors can be made during

7 characterization. In other words, as long as a parameter can be measured independently,

8 experimental errors can be made on this specific parameter.

9
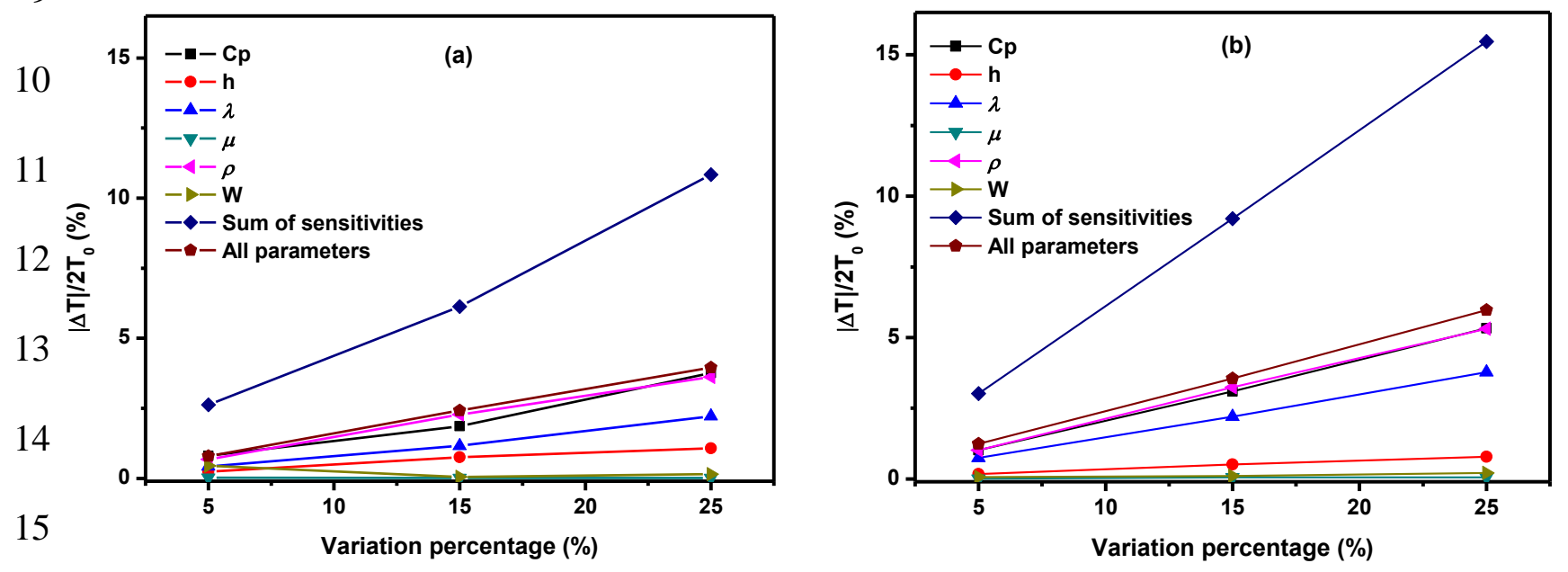

16

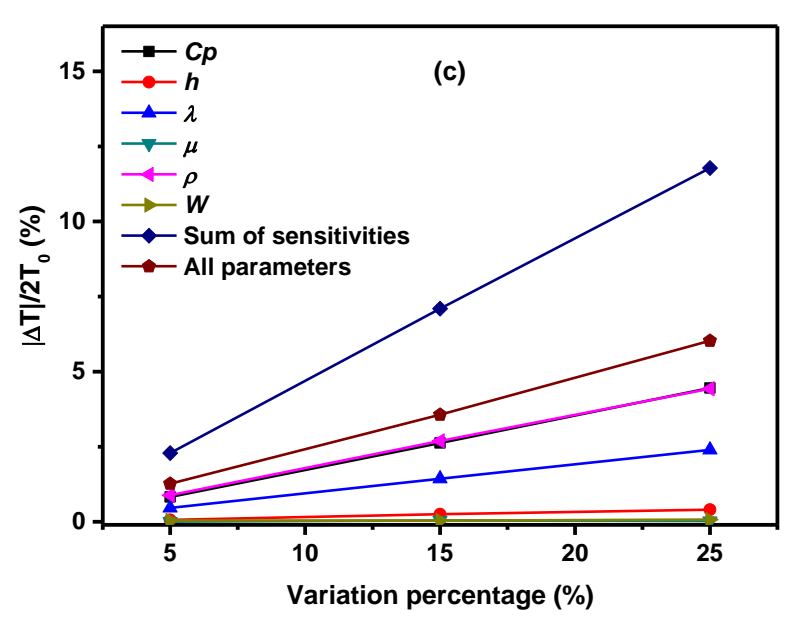

25 Fig. 12: Evolution of the temperature sensitivity versus the variation percentage of input parameters (with respect to their reference values), at different depths of the DPC wall: $3 \mathrm{~cm}$ 

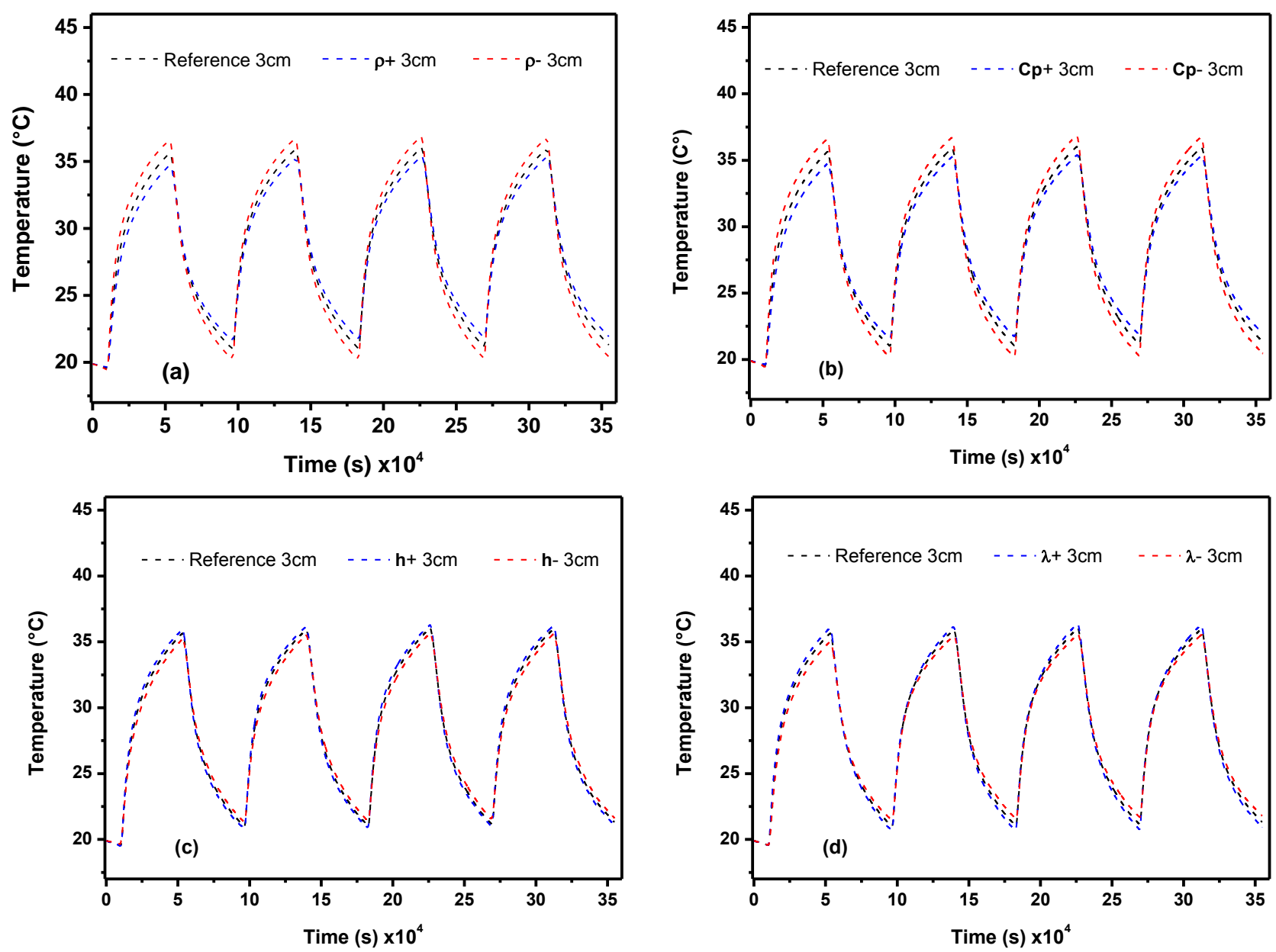

Fig. 13: New temperature profiles simulated at $3 \mathrm{~cm}$ depth in the DPC wall, considering $\pm 25 \%$ variations on (a) the material density $\rho$, (b) heat capacity $C_{p}$, (c) heat transfer coefficient $h$ and (d) thermal conductivity $\lambda$, compared to their reference values

\section{$4 \quad$ Moisture transfer (scenario 2)}

5 Regarding the simulation of RH profiles (corresponding to scenario 2), the instant chosen for 6 comparison of parametric sensitivities is $t=18 \times 10^{5} \mathrm{~s}$ for all depths. Fig. 14 shows the evolution 7 of the relative sensitivity versus the variation percentage of the model inputs. The graphs are 8 displayed for different depths of the DPC wall.

9 As previously noted in section 5.1.2, $\mu$ and $W$ are the most influencing parameters on moisture transfer, while the impact of the rest of parameters is negligible. This was expected, because

11 these two parameters describe respectively the moisture transfer and storage in the model. The 12 same result was obtained by Bart et al. [14] and Van Belleghem et al. [34]. 
1 It is important to note that porosity does not explicitly appear in the transfer equations.

2 However, it is implicitly taken into account through the measured reference properties, which

3 are determined assuming homogeneity of the DPC material. This may be the reason behind the

4 low effect of density $\rho$ on moisture transfer observed in this theoretical analysis. In reality, this

5 effect should be remarkable since porosity facilitates moisture diffusion. For instance, it was

6 shown that vapor permeability of hemp concrete blocks is influenced by the material density $\rho$

$7 \quad[19,35]$.

8

9

10

11

12

13

14

15

16

18 (a)
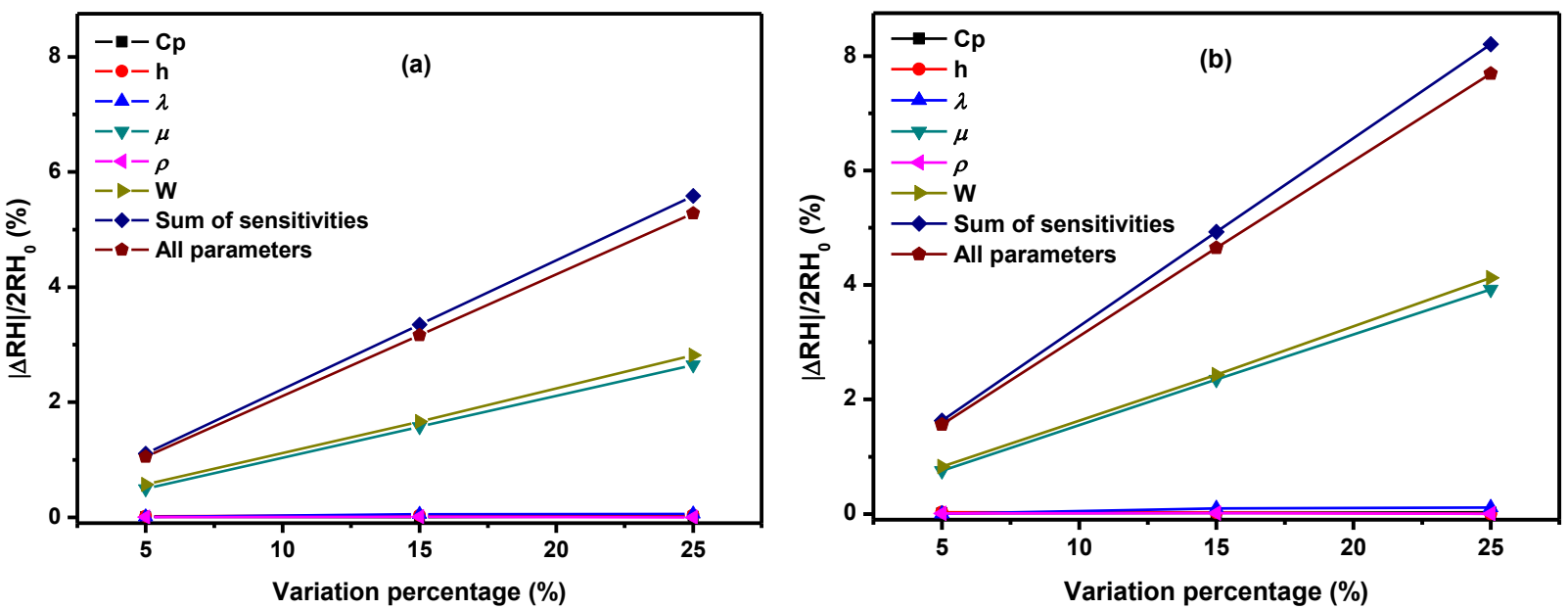

(c)

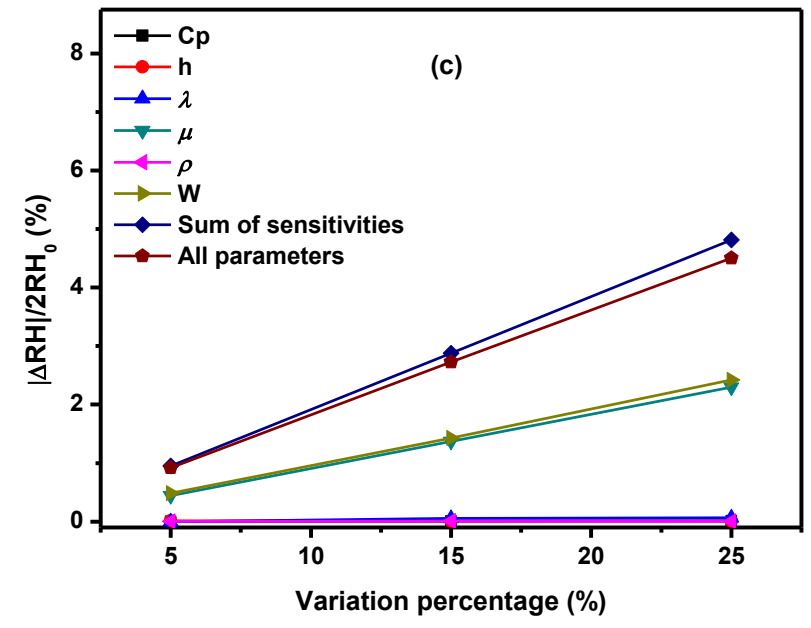

Fig. 14: Evolution of RH sensitivity versus the variation percentage of input parameters (with respect to reference values) at different depths of the wall: $3 \mathrm{~cm}(\mathrm{a}), 7.5 \mathrm{~cm}$ (b) and $12.5 \mathrm{~cm}$ (c)

Besides, varying all the parameters together provides high values of relative sensitivity on Fig. 14 , which are also very close to the sum of individual sensitivities. This result means that these material properties influence each other and that their uncertainties can accumulate and affect 
1 the model outcome to a large extend. It was previously shown on Fig. 10, that $25 \%$ variation

2 on the two main influencing parameters ( $\mu$ and $W$ ) have similar effects on theoretical profiles,

3 which explains the accumulation of errors observed in case 7 (simultaneous change in all

4 parameters).

$5 \quad$ Table 4: Comparison of sensitivity values for each case and each scenario at $7.5 \mathrm{~cm}$ depth

6 and considering $25 \%$ variation on the parameters

\begin{tabular}{cccc}
\hline $\begin{array}{c}\text { Sensitivity } \\
\text { per case }\end{array}$ & $\begin{array}{c}\text { Varying } \\
\text { parameters }\end{array}$ & $\begin{array}{c}\text { Scenario 1: heat } \\
\text { transfer }\end{array}$ & $\begin{array}{c}\text { Scenario 2: moisture } \\
\text { transfer }\end{array}$ \\
\hline Reference case & -- & -- & -- \\
\hline Case 1 & $C_{p}$ & $5.33 \%$ & $0.03 \%$ \\
\hline Case 2 & $h$ & $0.79 \%$ & $0.01 \%$ \\
\hline Case 3 & $\lambda$ & $3.77 \%$ & $0.11 \%$ \\
\hline Case 4 & $\mu$ & $0.05 \%$ & $3.92 \%$ \\
\hline Case 5 & $\rho$ & $5.31 \%$ & $0.01 \%$ \\
\hline Case 6 & $W$ & $0.21 \%$ & $7.13 \%$ \\
\hline $\begin{array}{c}\text { Case 7 } \\
\text { (simultaneous } \\
\text { variation) }\end{array}$ & $C_{p}, h, \lambda, \mu, \rho$, & $5.97 \%$ & $8.21 \%$ \\
\hline $\begin{array}{c}\text { Sum of } \\
\text { individual } \\
\text { sensitivities }\end{array}$ & $C_{p}, h, \lambda, \mu, \rho$, & $15.47 \%$ & \\
\hline
\end{tabular}

8 Table 4 shows the sensitivity values obtained for the different cases of scenario 1 compared

9 with scenario 2 at $7.5 \mathrm{~cm}$ depth and $25 \%$ of variation. We notice that the global model's

10 sensitivity to heat transfer problems is higher than the sensitivity to moisture transfer ones, as

11 a higher error accumulation risk is obtained.

12 A major reason behind these uncertainties, both in the scenarios of heat and moisture transfer,

13 relates to the material homogeneity assumption which is usually adopted at all scales in 14 experimental/numerical approaches. As a matter of facts, procedures used for material 15 preparation may represent a source of heterogeneity, especially at large scale (wall or building).

16 This can induce variations on measured material properties, and thus on the model inputs. 
1 Fig. 15 shows the effects of positive/negative changes in the values of $C_{p}$ and $\rho$ (one parameter

2 is varied while the other is kept constant at the reference value) on the relative temperature 3 sensitivity, as well as the influence of changing the values of $W$ and $\mu$ on RH sensitivity. The 4 effects of positive variations are found lower compared to those of negative changes. This was 5 also observed but not discussed in previous studies of the literature [2, 14, 34]. To our 6 knowledge, this is probably due to the nonlinear nature of the mathematical model, as the 7 coupled system involve several coefficients that depend on the system's unknowns and their derivatives. Moreover, our study takes place in a transient state where the system is in a continuous perturbation and varies over time. This is very different from a steady state study, where the system is in equilibrium and the sensitivities usually tends to constant values.
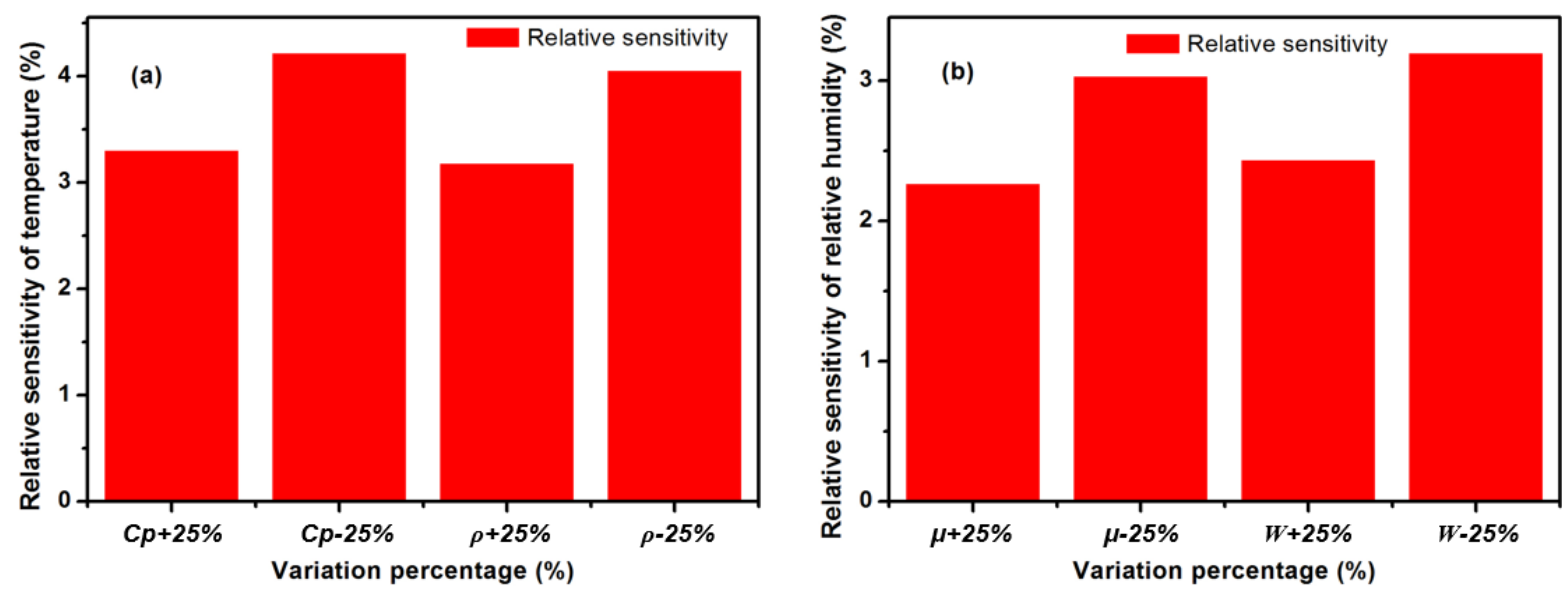

Fig. 15: Effects of variations $( \pm 25 \%)$ of selected parameters on the relative sensibility of the model: (a) influence of $C_{p}$ and $\rho$ on the temperature sensibility, and (b) influence of $W$ and $\mu$ on RH sensibility

\subsection{Effect of initial conditions and sensors position}

\subsubsection{Effect of initial conditions}

Figs. 16 and 17 show the effect of changing initial conditions on simulated profiles of temperature/RH at different depths. Regarding temperature profiles, and whatever the considered depth, these effects are mainly observed during the first heating phase and then rapidly vanish; the new profiles become very similar to the reference curve after a half cycle (about 82000s after the beginning of the test). Regarding RH profiles, these effects are more durable and can be observed throughout the test, but with lower influence at the end (deviation of about $0.55 \%$ on RH value compared to the reference curve at $t=18 \times 10^{5} \mathrm{~s}$ ). This result was 
1 expected, because of the slow kinetics of moisture transfer compared to heat transfer. It was

2 also reported by Oumeziane et al. [36], who studied the influence of initial moisture content 3 and relative humidity on the MBV tests; the authors concluded that the initial hygric state has 4 a strong impact on moisture transfer prediction, especially when hysteresis effect is taken into account. Globally, one must keep in mind that uncertainties on initial temperature conditions are relatively tolerated for long tests. Differently, uncertainties on RH conditions should be carefully evaluated, since errors as low as $\pm 2 \%$ can have a significant impact on numerical results.

\subsubsection{Effect of sensors position}

Fig. 18 shows the effect of changing the sensors position on simulated temperature profiles at different depths of the DPC wall. The largest deviation from the reference curve is obtained at $3 \mathrm{~cm}$ of depth and equals to $0.92{ }^{\circ} \mathrm{C}$, while at $7.5 \mathrm{~cm}$ and $12.5 \mathrm{~cm}$ of depths the maximum differences are $0.34{ }^{\circ} \mathrm{C}$ and $0.56{ }^{\circ} \mathrm{C}$ respectively. The effect of sensors position on numerical $\mathrm{RH}$ profiles at different depths is also shown in Fig. 19. Differences caused by a variation of \pm $1 \mathrm{~cm}$ from the reference position are more remarkable in this scenario (compared to scenario 1). The largest deviation on $\mathrm{RH}$ is also obtained at $3 \mathrm{~cm}$ depth (5.36\%), while smaller deviations of $1.66 \%$ and $1.65 \%$ are respectively found at $7.5 \mathrm{~cm}$ and $12.5 \mathrm{~cm}$ depths.

The accuracy of the sensors should also be taken into account in this analysis. In our case, the sensor accuracy specified by the manufacturer is $\pm 0.5^{\circ} \mathrm{C}$ on temperature and $\pm 1.8 \%$ on $\mathrm{RH}$ measurements. Temperature uncertainties are thus of the same order than temperature deviations resulting from the variation of sensors position, whereas $\mathrm{RH}$ uncertainties are much lower compared to RH deviations caused by errors on sensors position. Therefore, meticulous care should be taken while positioning the sensors on the experimental setup, especially for locations close to the outdoor surface of the wall where small errors may cause large data discrepancies. Similar conclusions were reported by Bart et al. [14], who studied the effect of sensors position on measured hygrothermal properties in the case of a $30 \mathrm{~cm}$ thick hemp concrete wall. 

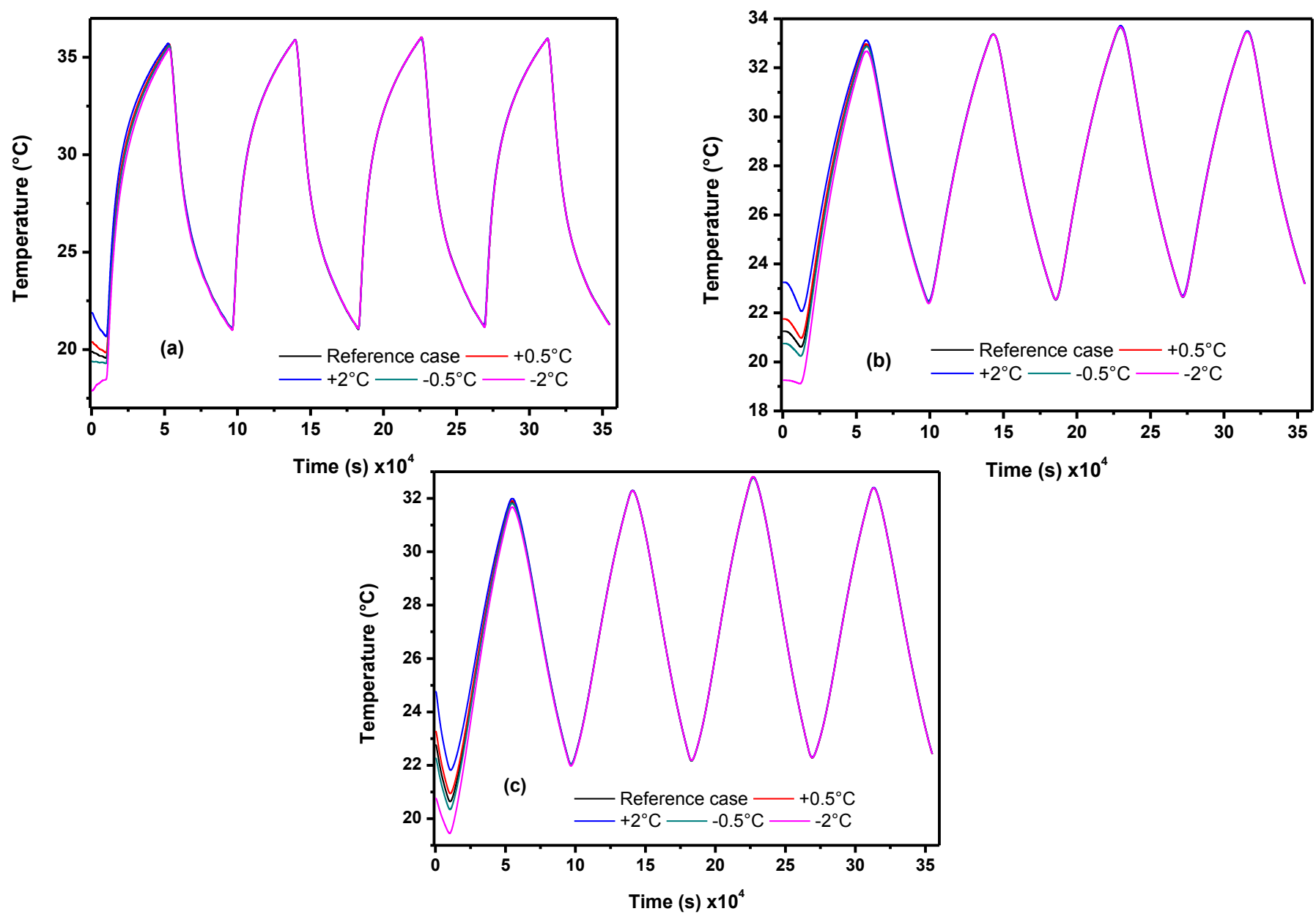

Fig. 16: Effect of changing initial temperature conditions on numerical temperature profiles obtained at different depths: $3 \mathrm{~cm}(\mathrm{a}), 7.5 \mathrm{~cm}$ (b) and $12.5 \mathrm{~cm}$ (c)

3

4

5 

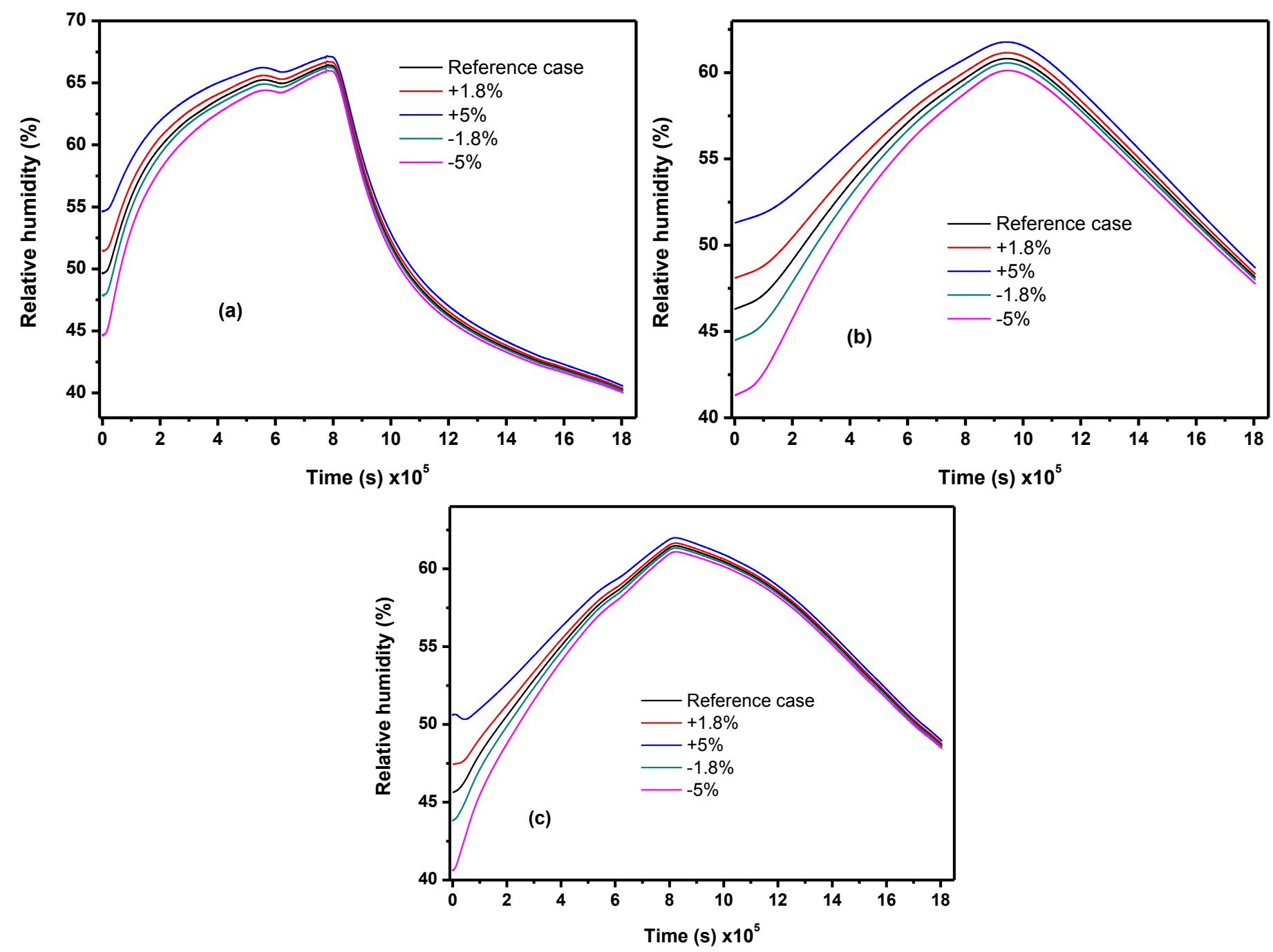

$1 \quad$ Fig. 17: Effect of changing initial RH conditions on numerical RH profiles obtained at

\section{$4 \quad 5.3 \quad$ simplified models}

\section{$5 \quad$ 5.3.1 Pure conduction model}

6 Fig. 20 displays the numerical temperature profiles provided by the model based on pure 7 conduction transfer only, and by the full Kunzel model (reference case), at different depths of 8 the DPC wall. Differences between the numerical outcomes of the pure conduction and full 9 models did not exceed $0.25{ }^{\circ} \mathrm{C}$, whatever the considered depth. This result shows that heat 10 conduction is the main transfer mode involved in the case of the DPC wall subjected to 11 conditions of scenario 1 . This is also validated by the fact that RH boundary conditions were 
1 kept unchanged, and hence any moisture motion was the result of heat transfer due to the 2 coupling effects between heat and moisture transfers (very small effect). This is translated mathematically by the phase change term in the right-hand side of Eq. 3, where the heat of phase change is related to vapor flux. In other words, this phase change term, which represents the only difference between the pure conduction and the full models, didn't play an important role in the studied case since the relative humidity was unchanged. Similar observations were noted by other authors on temperature profiles in the absence of phase change phenomena inside the material [31]. In such cases where only temperature changes are observed, one can conclude that the pure conduction model is sufficient to predict temperature profiles through a bio-based date palm concrete wall. This simplification provides a substantial gain of about $30 \%$ in calculation time.

\subsubsection{Neglecting liquid transfer}

Fig. 21 compares the numerical RH profiles obtained with the full Kunzel model (reference case) with those obtained with a simplified model neglecting liquid transfer. It can be noticed that the two models provide very different outcomes whatever the considered depth. Deviations on $\mathrm{RH}$ values increase during the adsorption phase, with differences up to $3.8 \%, 4 \%$ and $2.3 \%$ at $3 \mathrm{~cm}, 7.5 \mathrm{~cm}$ and $12.5 \mathrm{~cm}$ respectively. Conversely, the gap between the two models is less important during desorption phase and becomes even negligible at $3 \mathrm{~cm}$ depth. This result can be explained by the fact that liquid and vapor transfers play both important roles during the adsorption phase, while liquid transfer is less influent during the desorption phase. Liquid transfer is naturally present in the adsorption phase, mainly through a surface diffusion process that starts to appear earlier in the hygroscopic region [11]. This process contributes to moisture transfer and accelerates its kinetics. Therefore, the full model provides numerical RH profiles that rise faster during adsorption phase and decrease faster during desorption phase, compared to the simplified model. Consequently, it is recommended not to neglect liquid transfer when modeling moisture transfer in porous building materials. 

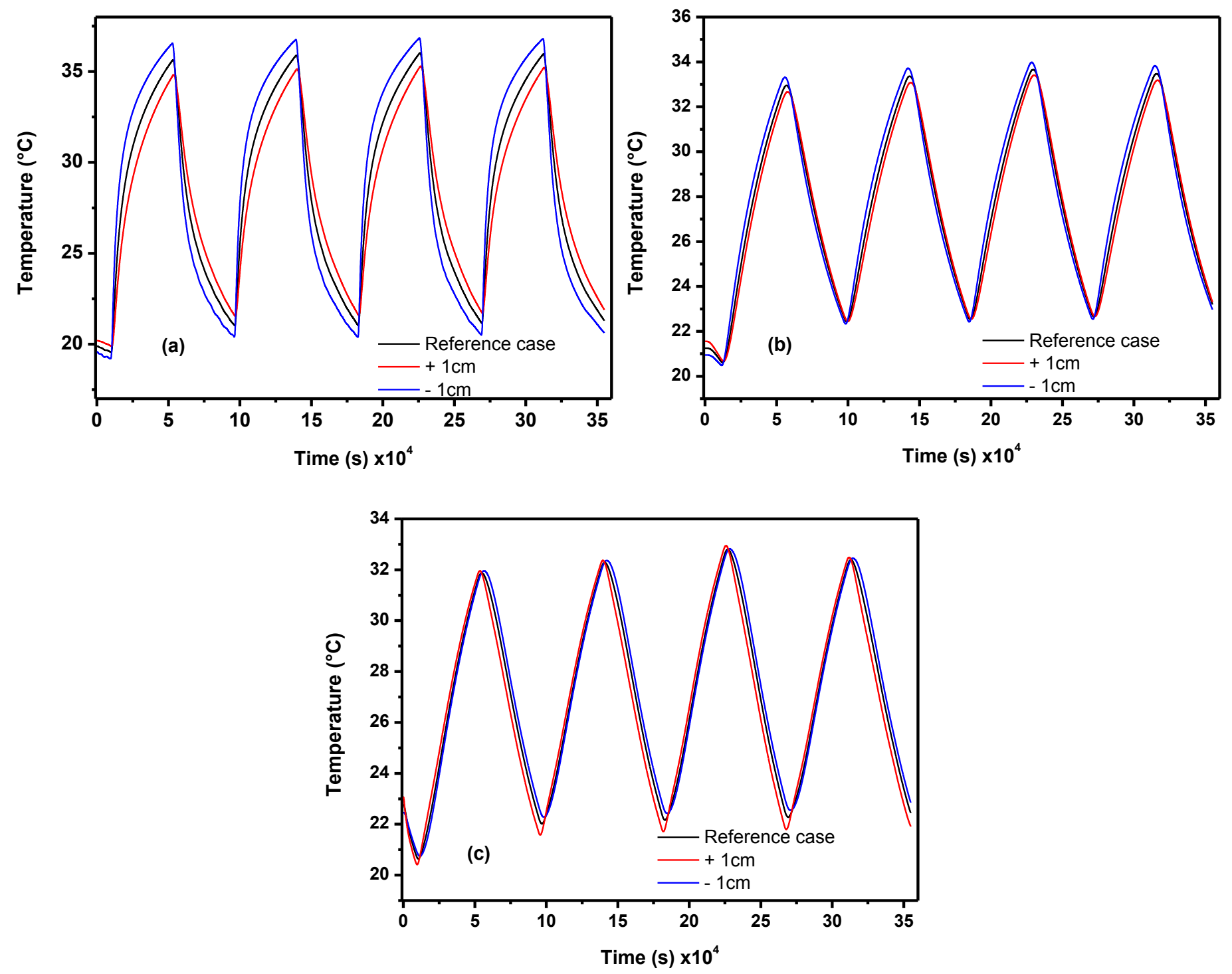

2 Fig. 18: Effect of changing sensors position on numerical temperature profiles determined at 3 different depths of the DPC wall: $3 \mathrm{~cm}(\mathrm{a}), 7.5 \mathrm{~cm}(\mathrm{~b})$ and $12.5 \mathrm{~cm}(\mathrm{c})$

4

5 

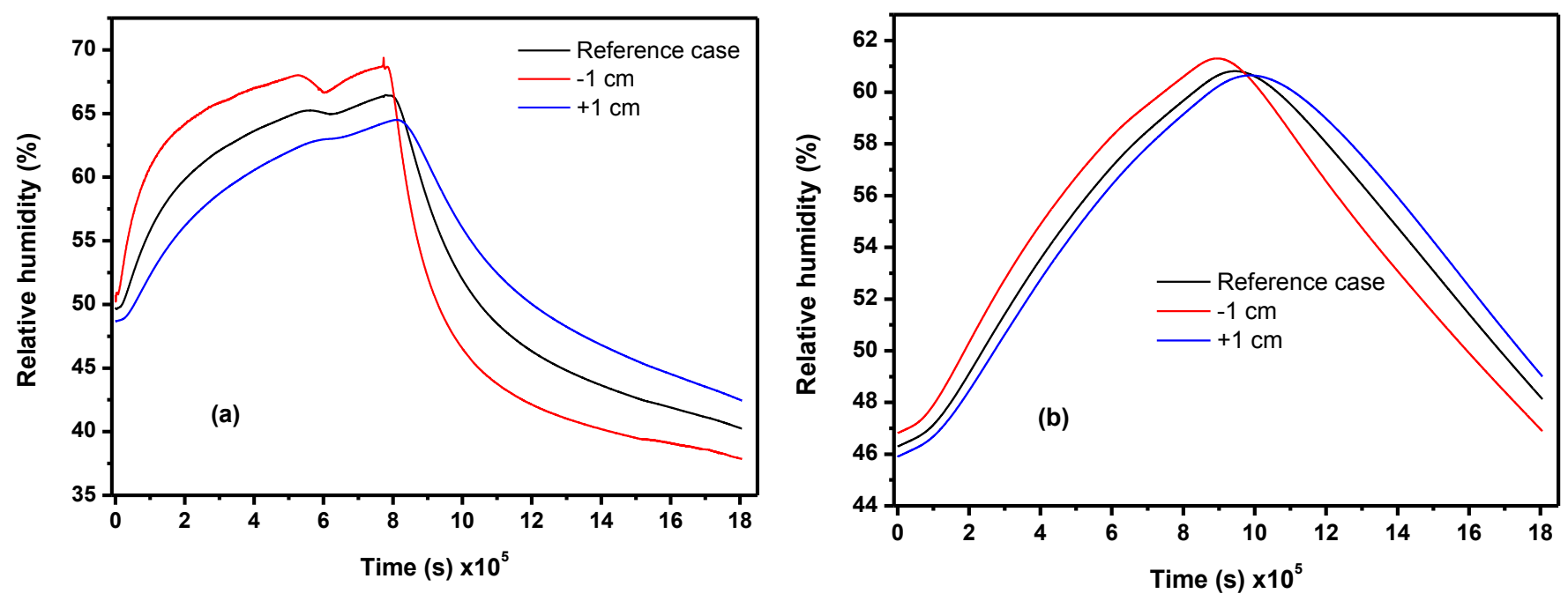

2

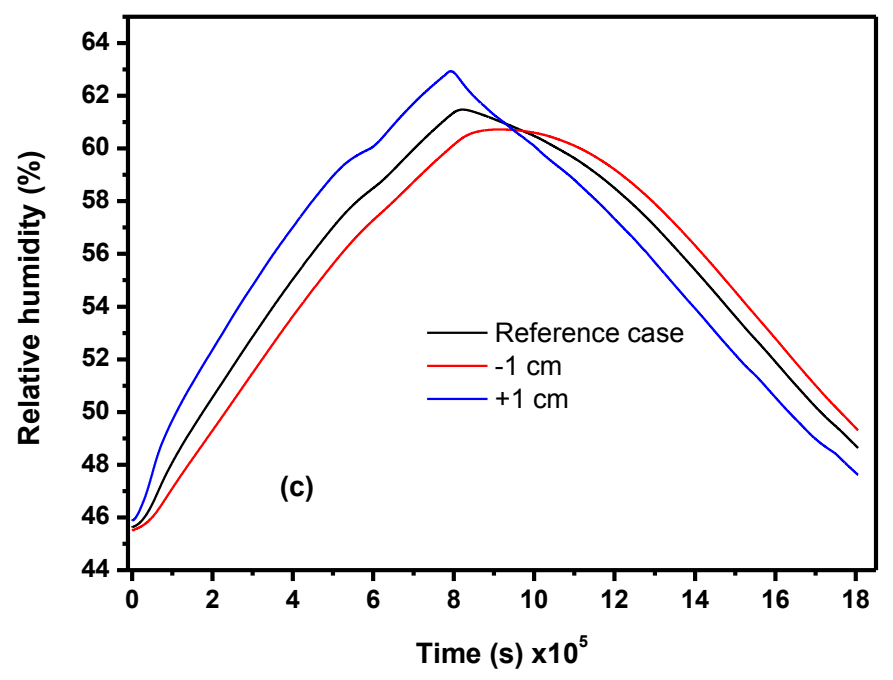

3

$4 \quad$ Fig. 19: Effect of changing sensors position on numerical RH profiles determined at different 5 depths of the DPC wall: $3 \mathrm{~cm}(\mathrm{a}), 7.5 \mathrm{~cm}(\mathrm{~b})$ and $12.5 \mathrm{~cm}$ (c) 

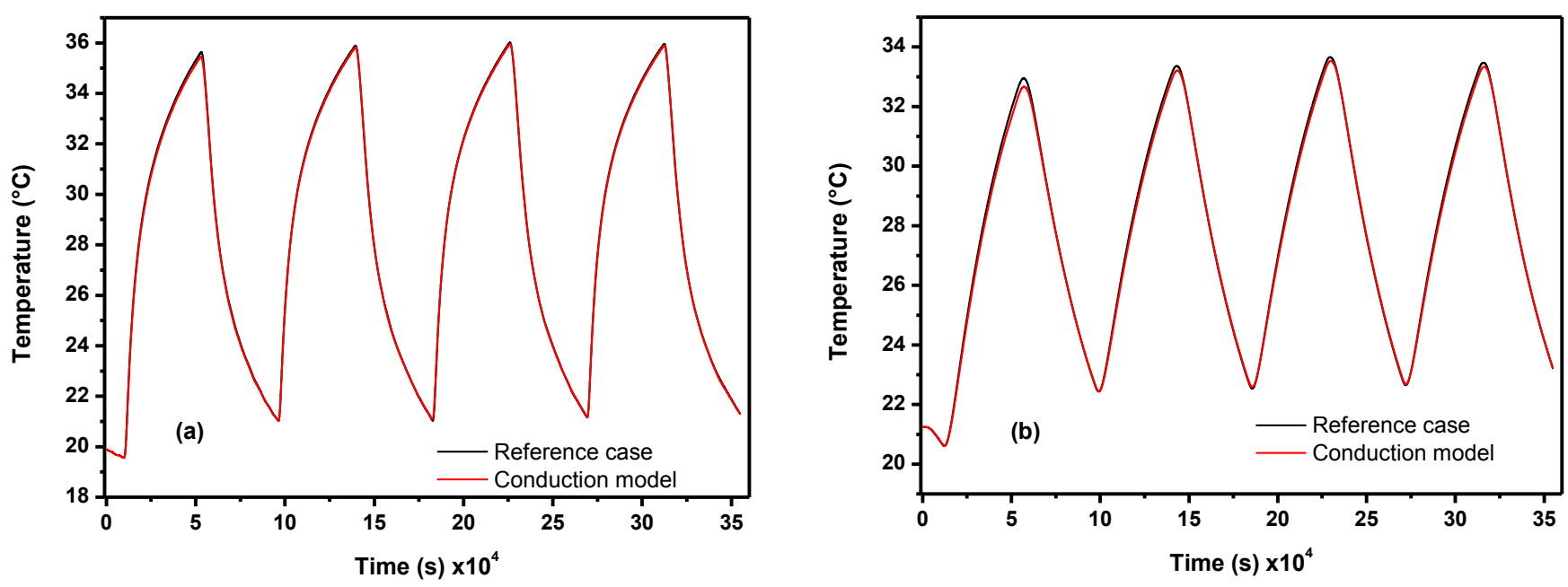

2

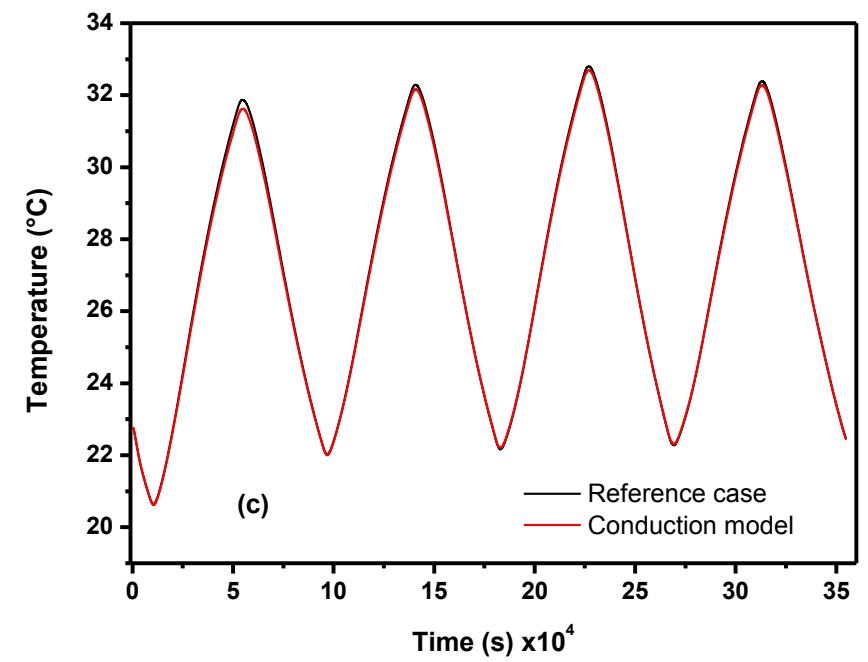

3

4

$5 \quad$ Fig. 20: Comparison of numerical temperature profiles provided by the pure conduction 6 model and by the full Kunzel model (reference case), at different depths of the DPC wall: 3 7 $\mathrm{cm}(\mathrm{a}), 7.5 \mathrm{~cm} \mathrm{(b)} \mathrm{and} 12.5 \mathrm{~cm}(\mathrm{c})$ 

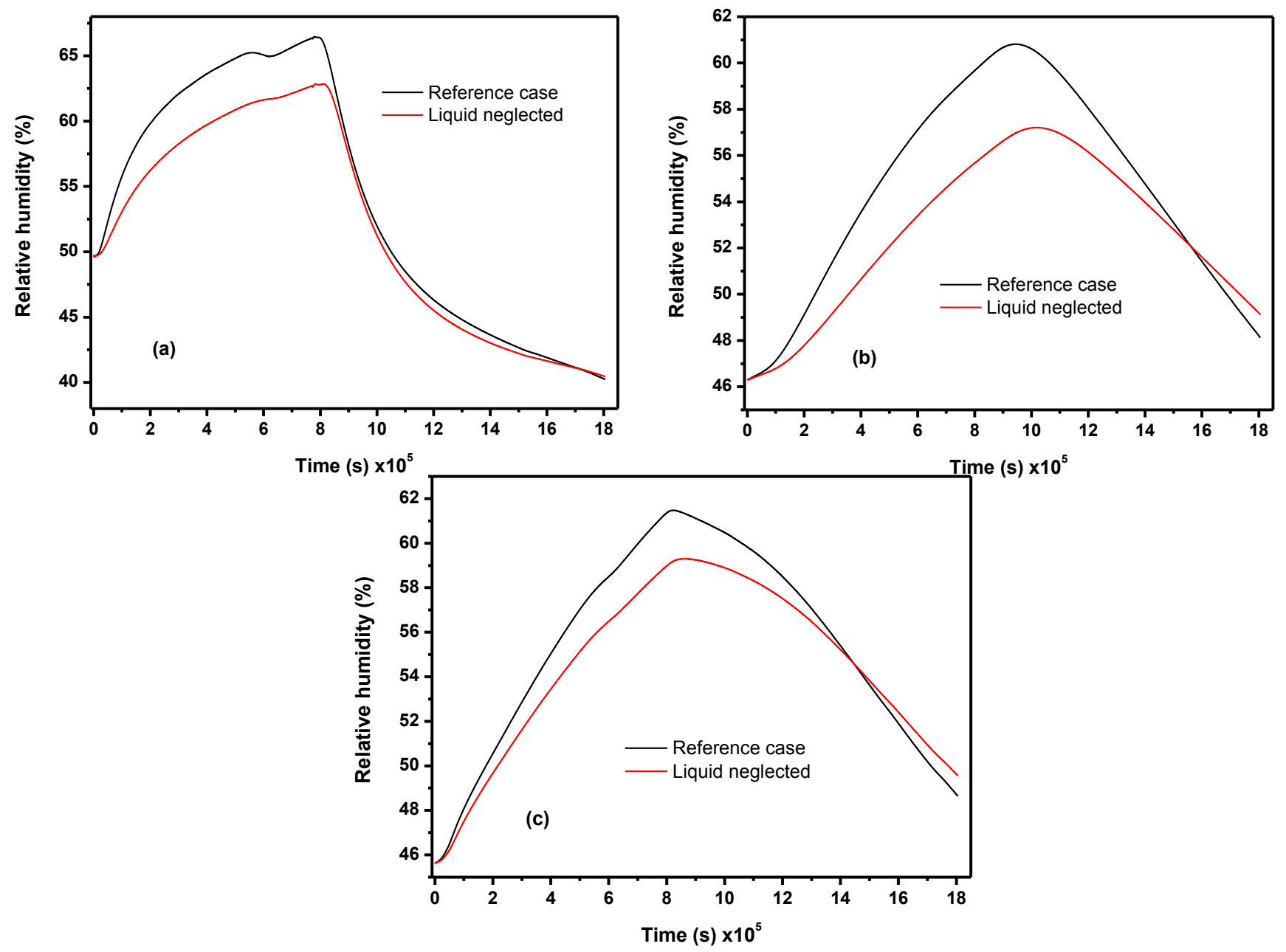

3 Fig. 21: Comparison of numerical RH profiles provided by the model neglecting liquid 4 transfer mode and by the full Kunzel model (reference case), at different depths of the DPC 5 wall:3 cm (a), $7.5 \mathrm{~cm}$ (b) and $12.5 \mathrm{~cm}$ (c) 


\section{Conclusion}

2 In this work, a parametric sensitivity analysis was carried out on the transient heat and moisture 3 transfer response of Kunzel's model. This model was applied to simulate the hygrothermal 4 behavior a wall made of Date Palm Concrete (DPC), and boundary conditions for heat and moisture transfer scenarios were imported from real experiments. The effects of finite variations of the model inputs (reference material parameters and initial conditions) on the numerical outcome were investigated.

8 The results showed that the theoretical description of heat transfer is very influenced by changes in the heat capacity $C_{p}$ and density $\rho$, which generates errors on temperature profiles reaching about $5.3 \%$ in terms of relative sensitivity. On the other hand, parameters

11 influencing moisture transfer are mainly the sorption isotherm $W$ and the vapor resistance factors $\mu$, which are responsible for a relative sensitivity of $4 \%$ on RH profiles. Therefore, a particular attention should be paid to the experimental determination of these reference properties at the material scale, and their validity at higher scales (wall or building) should be verified as well. It was also noted that moisture transfer is very sensitive to any errors in the initial conditions and sensors position. Uncertainties on initial RH values may influence the results even in the case of long tests (18 days' test in our case). Furthermore, uncertainties of

$18 \pm 1 \mathrm{~cm}$ on the sensors position may lead to $5.36 \%$ deviation on $\mathrm{RH}$ profiles.

Finally, some terms were neglected in the model, such as the heat of phase change and liquid diffusion, in order to explore the possibility of simplifying the model. It was shown that a pure conduction model is able to accurately describe the heat transfer process, whereas neglecting liquid diffusion leads to significant underestimations in $\mathrm{RH}$ profiles during the adsorption phase and should thus be proscribed.

\section{Acknowledgements:}

This research was conducted with the financial support of PHC TASSILI Project 16MDU976. 
[1] M. Haddadi, B. Agoudjil, N. Benmansour, A. Boudenne and B. Garnier, "Experimental and modeling study of effective thermal conductivity of polymer filled with date palm fibers", Polymer Composites, vol. 38, p. 1712-1719, 2015.

[2] A. T. Le, C. Maalouf, T. H. Mai, E. Wurtz and F. Collet, "Transient hygrothermal behaviour of a hemp concrete building envelope", Energy and buildings, vol. 42, pp. 1797-1806, 2010.

[3] L. Liu, H. Li, A. Lazzaretto, G. Manente, C. Tong, Q. Liu and N. Li, "The development history and prospects of biomass-based insulation materials for buildings", Renewable and Sustainable Energy Reviews, vol. 69, pp. 912-932, 2017.

[4] M. Rahim, O. Douzane, A. T. Le, G. Promis, B. Laidoudi, A. Crigny, B. Dupre and T. Langlet, "Characterization of flax lime and hemp lime concretes: Hygric properties and moisture buffer capacity", Energy and Buildings, vol. 88, p. 91-99, 2015.

[5] M. Labat, C. Magniont, N. Oudhof and J. E. Aubert, "From the experimental characterization of the hygrothermal properties of straw-clay mixtures to the numerical assessment of their buffering potential", Building and Environment, vol. 97, pp. 69-81, 2016.

[6] B. Agoudjil, A. Benchabane, A. Boudenne, L. Ibos and M. Fois, "Renewable materials to reduce building heat loss: Characterization of date palm wood", Energy and Buildings, vol. 43, p. 491-497, 2011.

[7] M. Barletta, S. Guarino, G. Rubino, F. Trovalusci and V. Tagliaferri, "Environmentally friendly wooden-based coatings for thermal insulation: Design, manufacturing and performances", Progress in Organic Coatings, vol. 77, pp. 701-711, 2014.

[8] J. Lazko, B. Dupré, R. M. Dheilly and M. Quéneudec, "Biocomposites based on flax short fibres and linseed oil", Industrial crops and products, vol. 33, pp. 317-324, 2011.

[9] M. Caniato, L. Cozzarini, C. Schmid and A. Gasparella, "Acoustic and thermal characterization of a novel sustainable material incorporating recycled microplastic waste", Sustainable Materials and Technologies, vol. 28, no. e00274, 2021.

[10] J. R. Philip and D. A. De Vries, "Moisture Movement in Porous Materials under Temperature Gradients", Transactions American Geophysical Union, vol. 38, pp. 222232, 1957.

[11] H. M. Künzel, Simultaneous heat and moisture transport in building components. Oneand two-dimensional calculation using simple parameters, Stuttgart: IRB-Verlag, 1995.

[12] T. Alioua, B. Agoudjil, N. Chennouf, A. Boudenne and K. Benzarti, "Investigation on heat and moisture transfer in bio-based building wall with consideration of the hysteresis effect", Building and Environment, vol. 163, no. 106333, 2019.

[13] WUFI®, WUFI®, [Online]. Available: https://wufi.de/en/software/validation/. 
[14] M. Bart, S. Moissette, Y. Ait Oumeziane and C. Lanos, "Transient hygrothermal modelling of coated hemp-concrete walls", Journal of Environmental and Civil Engineering, vol. 18, pp. 927-944, 2014.

[15] I. Othmen, P. Poullain and N. Leklou, "Sensitivity analysis of the transient heat and moisture transfer in a single layer wall", European Journal of Environmental and Civil Engineering, vol. 24, no. 13, pp. 1-19, 2018.

[16] J. Morio, "Global and local sensitivity analysis methods for a physical system", European journal of physics, vol. 32, no. 1577, 2011.

[17] H. M. Wainwright, S. Finsterle, Y. Jung, Q. Zhou and J. T. Birkholzer, "Making sense of global sensitivity analyses", Computers \& Geosciences, vol. 65, pp. 84-94, 2014.

[18] N. Mendes, F. Winkelmann, R. Lamberts and P. Philippi, "Moisture effects on conduction loads", Energy and Buildings, vol. 35, p. 631-644, 2003.

[19] Y. Aït Oumeziane, S. Moissette, M. Bart, F. Collet, S. Pretot and C. Lanos, "Influence of hysteresis on the transient hygrothermal response of a hemp concrete wall", Journal of Building Performance Simulation, vol. 10, pp. 256-271, 2017.

[20] B. Haba, B. Agoudjil, A. Boudenne and K. Benzarti, "Hygric properties and thermal conductivity of a new insulation material", Construction and Building Materials, vol. 154, p. 963-971, 2017.

[21] N. Benmansour, B. Agoudjil, A. Gherabli, A. Kareche and A. Boudenne, "Thermal and mechanical performance of natural mortar reinforced with date palm fibers for use as insulating materials in building", Energy and Buildings, vol. 81, p. 98-104, 2014.

[22] N. Chennouf, B. Agoudjil, A. Boudenne, K. Benzarti and F. Bouras, "Hygrothermal characterization of a new bio-based construction material: Concrete reinforced with date palm fibers", Construction and Building Materials, vol. 192, pp. 348-356, 2018.

[23] E. I. 12572, "Hygrothermal performance of building materials and products Détermination of water vapour transmission properties - Cup method", BS EN ISO 12572, 2016.

[24] E. I. 15148, "Hygrothermal performance of building materials and products Determination of water absorpion coefficient by partial immersion", EN ISO, 2002.

[25] E. I. 12571, "Hygrothermal performance of building materials and products Détermination of hygroscopic sorption properties", BS EN ISO, 2013.

[26] S. Brunauer, P. H. Emmett and E. Teller, "Adsorption of gases in multimolecular layers", Journal of the American chemical society, vol. 60, no. 2, pp. 309-319, 1938.

[27] N. Chennouf, B. Agoudjil, T. Alioua, A. Boudenne and K. Benzarti, "Experimental investigation on hygrothermal performance of a bio-based wall made of cement mortar filled with date palm fibers", Energy and Buildings, vol. 202, no. 109413, 2019. 
[28] T. Alioua, B. Agoudjil, N. Chennouf, A. Boudenne and K. Benzarti, "Dataset on the hygrothermal performance of a date palm concrete wall", Data in brief, vol. 27, no. 104590, 2019.

[29] T. Colinart, D. Lelièvre and P. Glouannec, "Experimental and numerical analysis of the transient hygrothermal behavior of multilayered hemp concrete wall", Energy and Buildings, vol. 112, pp. 1-11, 2016.

[30] A. Boudenne, L. Ibos and Y. Candau, "Analysis of uncertainties in thermophysical parameters of materials obtained from a periodic method", Measurement Science and Technology, vol. 17, no. 1870, 2006.

[31] Y. A. Oumeziane, Evaluation des performances hygrothermiques d'une paroi par simulation numérique: application aux parois en béton de chanvre, Rennes: Doctoral dissertation, 2013. https://hal.archives-ouvertes.fr/tel-00871004/

[32] COMSOL Multiphysics user's guide, COMSOL Multiphysics, 2008.

[33] A. T. Le, Etude des transferts hygrothermiques dans le béton de chanvre et leur application au bâtiment, Reims: Doctoral dissertation, 2010. https://tel.archivesouvertes.fr/tel-00590819/

[34] M. Van Belleghem, H. J. Steeman, M. Steeman, A. Janssens and M. De Paepe, "Sensitivity analysis of CFD coupled non-isothermal heat and moisture modelling", Building and Environment, vol. 45, pp. 2485-2496, 2010.

[35] F. Collet and S. Prétot, "Thermal conductivity of hemp concretes: Variation with formulation, density and water content", Construction and building materials, vol. 65, pp. 612-619, 2014.

[36] Y. A. Oumeziane, M. Bart, S. Moissette and C. Lanos, "Hysteretic behaviour and moisture buffering of hemp concrete", Transport in porous media, vol. 103, pp. 515$533,2014$. 